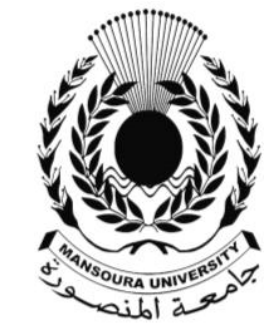

جامعة المنصـورة المانفة

$$
\text { كليـة الآداب }
$$

\title{
كتاب البوابات بمقبرة ثا نفر(TT 158) بطيبة
}

\section{sleel}

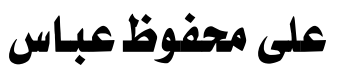 \\ مدير المخزن المتحفي بتل الربع \\ تفتيش آثار الدقهلية \\ المجلس الأعلى للآثار - وزارة الآثار
}

أيهن وهبى طاهر

استاذ الاثار المصرية القديمة المساعد بقسم الآثار

المصرية القديمة ،كلية الآداب- جامعة المنصورة

$$
\text { مجــلة كلــية الآداب - جامعــة المنصـورة }
$$




\section{كتاب البوابات بمقبرة \\ ثنا نفر (TT 158) بطيبة}

على محفوظعباس

أيهن وهبى طاهر

المُلخص

تتناول الورقة البحثية العناظر والنصوص التى تمثل كتاب البوابات على جدران مقبرة ثا نفر رقم 101 بذراع أبو النجا بغرب

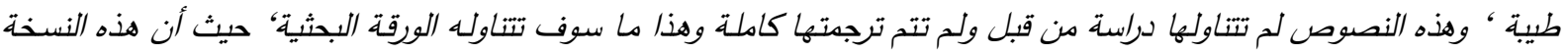

تعد من النسخ النادرة لتصوير كتاب البوابات على جدران مقبرة غير ملكية أو أحد أفراد العائلة الملكية.

\section{Abstract}

The present Study deals with the scenes and texts of the Book of Gates on the walls of the tomb of Tjanefer (TT158) at Dra-Abul Naga in west Thebes, these texts have not been fully studied before, the present paper is trying to full this gap, because this copy of the book of Gates is considered as a rare copy depicted on non-royal tomb or one of the royal family tomb.

الكلمات الدالة

\section{Keywords}

Tjanefer- Book of Gates- hours- Re- gate- Netherworld- Osiris

$$
\text { ثا نفر -كتاب البوابات- الساعات- رع- البوابة- العالم الآخر - أوزير }
$$

مقدمة

كُتب اسمه فى مقبرته بعدة هيئات: (

387(2)

*A nfr
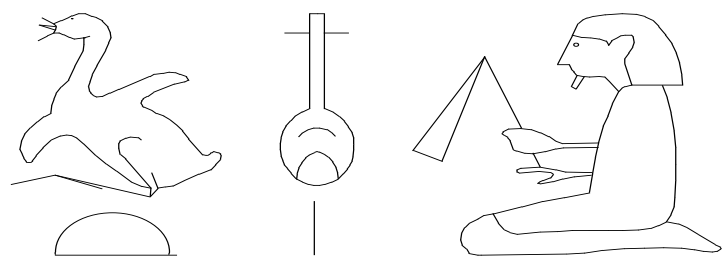

وصف المقبرة تقع مقبرة ثا نفر فى الجزء

الأعلى مسن جبانـة ذراع ابـو النجـا وتحمـل رقـم

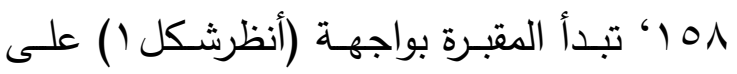

هيئسة صـرحين يكتنفــان مــخل الفنـاء المفتـوح

المحاط بمجموعـة من الأعمدة يؤدى الفناء فى هي

نهايته إلى صالة مستعرضة ثم تفضى إلى صالة طولية أو ممر طولى نقش على جدرانه الشمالية والجنوبيـة منــاظر مـن كتـاب البوابـات، يـؤدى في المــر فـى نهايتـهـ إلـى حجـرة الـدفن وبـداخلها

المقصـورة (أنظر شـكل r) , Seele 1959, pl.41;PM I'2,268 (185), plan 264.map II, D-6,c,I.) 


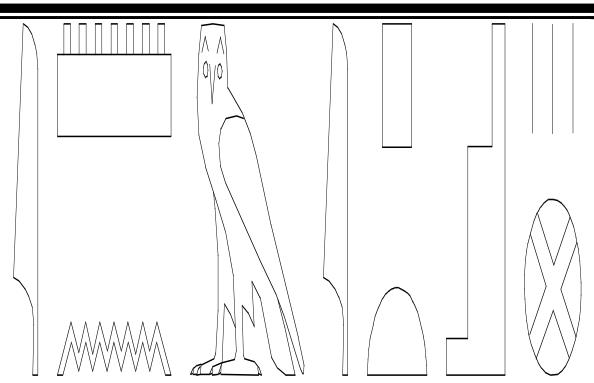

هوالكاهن الثالث والأب الإلهى ومطهر أيدى آمـون فى الكرنـك وكـاهن السم فـى أفق الأبديـة

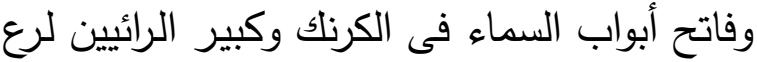
آتوم فى طيبة" (Seele 1959,5).عاش ثا نفر وزوجته خلال فترة الأسرة التاسعة عشر (عاصركلا من رمسيس الثانى ومرنبتاح وآمون مس وسبتاح وسـتى الثانى) حتى بدايـة الأسـرة العشـرين فى في

عصرست نخت ورمسيس الثالث ( Seele) 1959,7; Maninche 2011,7 آمون حتب وأمه تدعى حنوت متر وزوجته تدعى الدى نفرتـارى وحملت لقب" كبيـرة حريم آمـون" وهى حفيدة الكاهن الأكبر لآمسون باك إن خنسو من زوجته المدعوة مرت سجر (Seele 1959, 6)

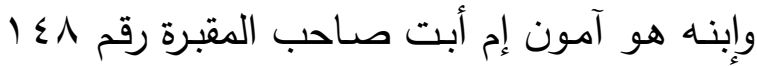
فى جبانـة ذراع أبو النجا والتى تؤرخ بعهد الملك إلك رمسـيس الخـامس فـى الأســرة العشـرين (cf.Gaballa and Kitchen 1981, 160181; Ockinga 2009; $\mathrm{PM} \mathrm{I}^{2}$, 259-260) الارراسات السابقة للمقبرة ذُكرت بعضـا من منـاظر ونصوص المقبرة فى دراسات سابقة مثل شامبليون الذى زار المقبرة

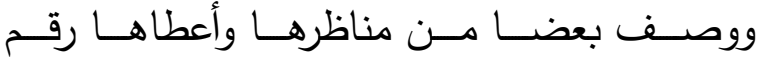
§ §cf.Champollion 1844) ثم لبسيوس الذى وصف بعض مناظر المقبرة وأخذ منها جزءاً مـن منظر العـازف على الهارب وأهداه لمتحف

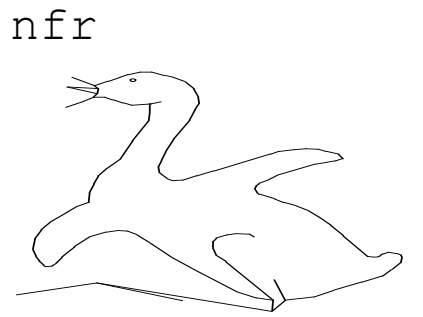

$\star \mathrm{A}$

كتب لقبه ضمن نصوص مقبرته بالصور

التالية (5eele 1959, 4-5)

Hm nTr الكاهن
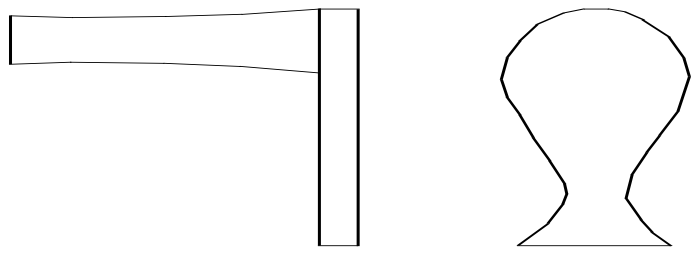

Hm nTr الكاهن الأول
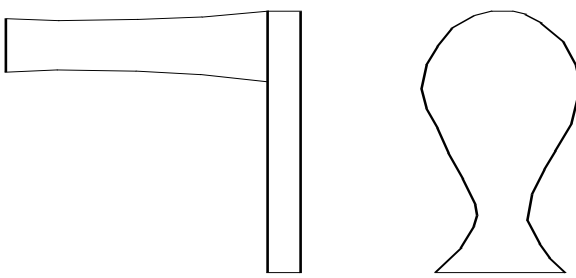

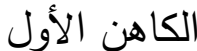

$\mathrm{Hm}$

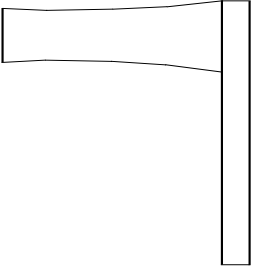

nTrtpy
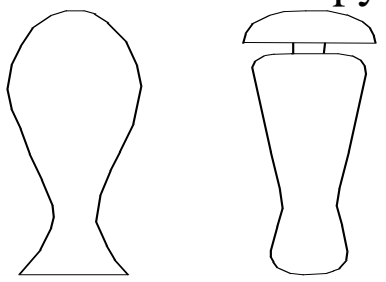

الكاهن الثالث Hm nTr xmnw-nw
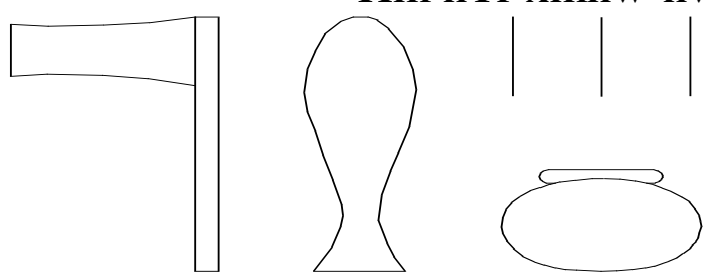

لآمون فى الكرنك nImnIptswt 
الأول(cf.Bonomi and Sharpe1864; SStephen 2010

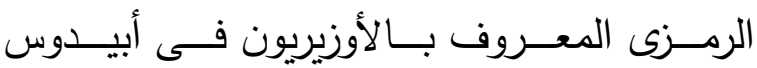
(cf.Frankfort 1933)

لـم ينتشـر تصــوير كتــاب البوابـات علـى مقابرالأفراد في عصر الدولة الحديثة سوي على

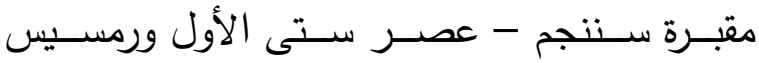

الثانى - بدير المدينـة Bruyère1959; Shedid1994; Haring2006) أراد ان يضمن بوابات العالم الآخر ضمن مناظر ونصوص مقبرته فنراه يصورعشر بوابات يحرسها مجموعة من الأرواح الحارسة على جدران حجرة فئران الدفن على الجدار الشمالى فى المستوى العلوى الارى من الجانب الثرقى والمنظر يتطابق مـع فصول

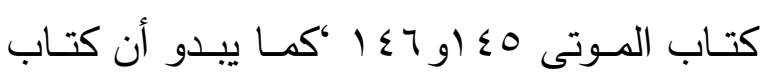
البوابات قد تطور عن كتاب الطريقين المعروف ضمن متون التوابيت حيث ذكرت بوابات العالم الآخــر السـبعة وكــان علـى المتـوفى أن يجتــاز

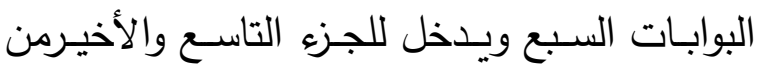
النص-طبقا لتقسيم ( Lesko 1972$)$ النهاية المحتمة للرحلة حيث يلتقى المتوفى مـع

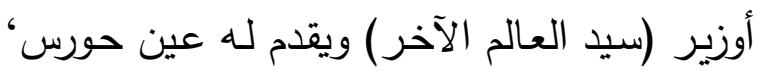

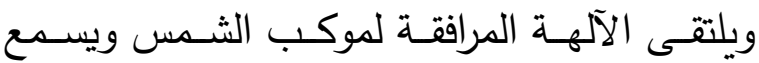

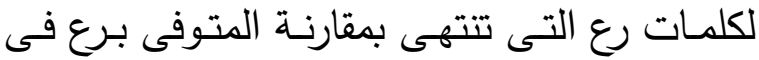

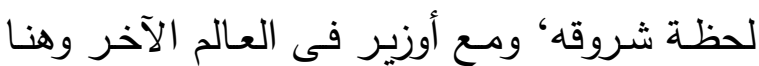
تتنهى رحلته بسعادة (CT1130). كما استطاعت نفرتارى كزوجة ملكية كبرى للملك رمسيس الثانى أن تصور أجزاء من كتاب

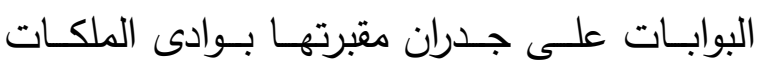

برلين كما أخذ معـه بعض الكارتونـاج الخـاص

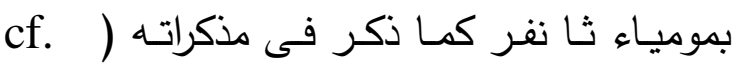
1900 Varille (العازف على الهارب من مقبرة ثا نفر

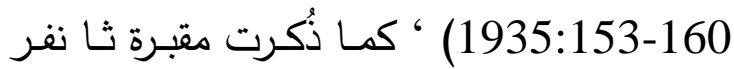
ضمن نصوص بردية سرقات الدقابر التى وقعت فى عصر الملك رمسيس التاسع ( cf. Peet

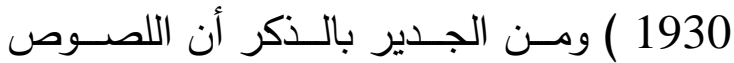
ذكروا ثا نفر بأنه الكاهن الثالث. أرخ جـاردنر المقبرة بعصر مرنبتاح cf. Gardiner and

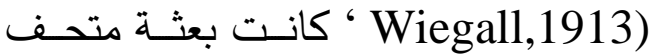
بنسلفانيا قد درست وصورت بعضا من مناظر

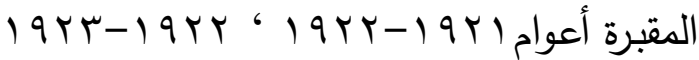
(Seele ثم قام)(Fisher 1924:28-49) (1959بنشـر منـاظر المقبـرة كاملـة مـع عهل تخطـيط للمقبـرة ومقدمـة عـن صـاحب المقبـرة وعائلته وعلاقته بكهنوت طيبة ولكنه لم يقدم وصفا وتحليلا للمناظر والنصوص.

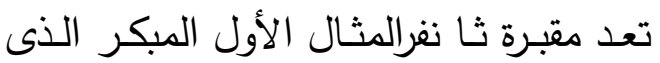

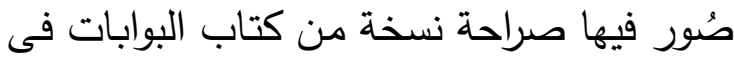
مقابر الأفراد، لقد تم تصوير كتاب البوابات منذ هنا هنه

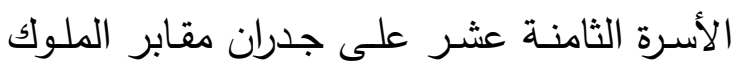
(cf.Hornung1971) جدران مقابر الملوك حتى نهاية الدولة الحديثة (cf. Hornung 1979-1980; ) Zandee1969; Piankoff and Maystre 1939-1962 كمــا تـم تصـويره على توابيـت

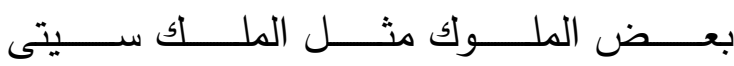




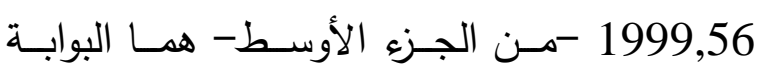

cf. McDonalde 1996; Shedid1990; )

ومركب الثمس بطاقمها ومجموعة الآلهة الذين "Wildung 1984 يقومون بسحبها ويظهر صـاحب المقبرة أمام كل جدران حجرة الدفن' ( PM I²,762-765)

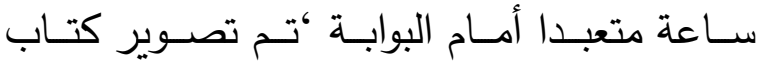
وحيث أن نفرتارى من العائلـة البوابات على الجدار الجنوبى والجدار الثـمالى المالكة فمن المقبول أن تحصل على نسخة من

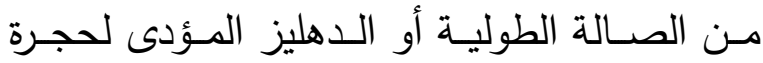
كتابات البوابات على جدران مقبرتها بينما كان الدفن والمقصورة .(شكل r) محظورا استخدامه على الأفراد فى الأسرة الثامنة أولا: تصوير كتاب البوابات على الجدار الجنوبي

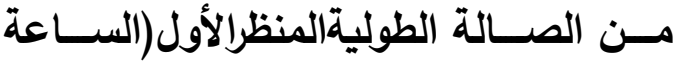
الأولى من كتاب البوابات) (شكل r )

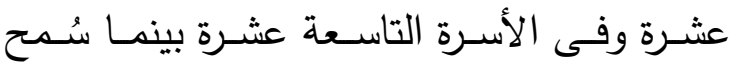
للمدعو ثا نفر أن يزين مقبرته فى ذراع أبو النجا

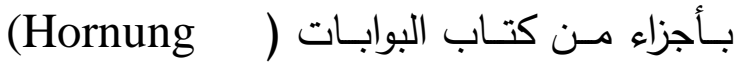
المنظر مهم بدرجة كبيرة ويمكن فقط مشاهدة ثا نفرواقفا متعبدا مرتديا جلد الفهدوأمامه بقايا نقش:

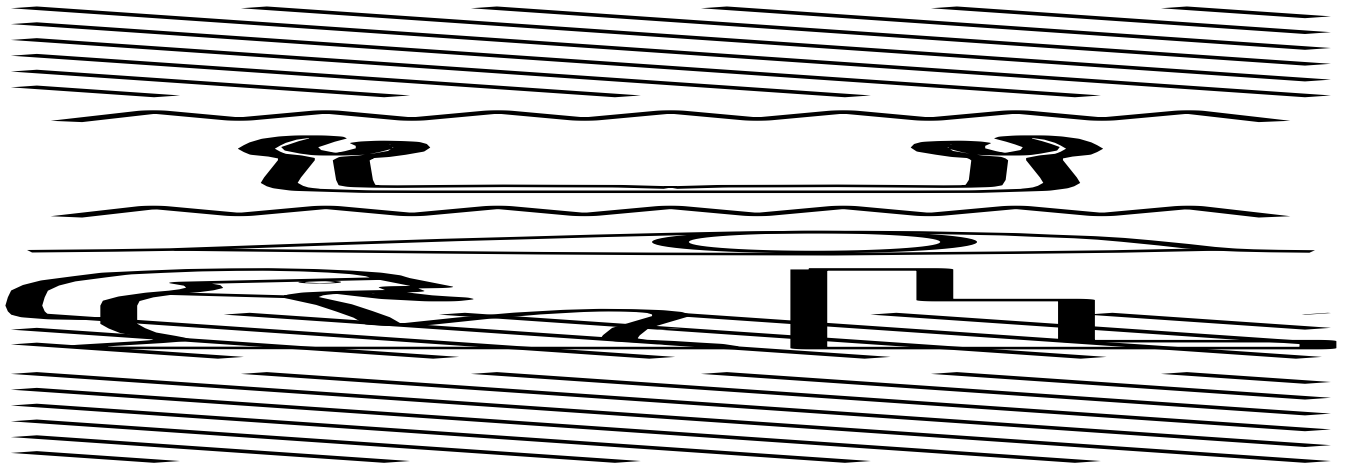

$$
\begin{aligned}
& \text {.... n kA n Wsir ...... } \\
& \text { ".............. لأجل كا أوزير ل }
\end{aligned}
$$

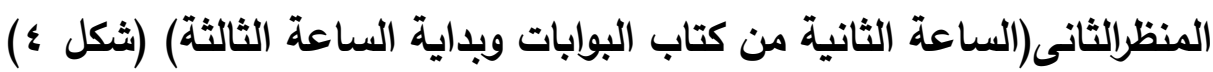
يبدأ المنظرمن اليساربوابة تزينها زخرفة الغكر ويحرسها من اعلى حية كوبرا ومن الأمام مومياوات

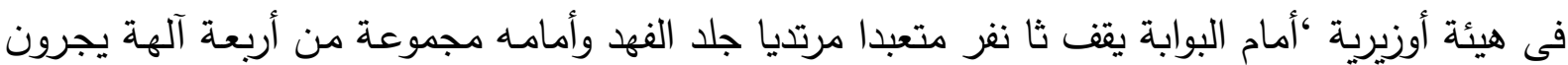

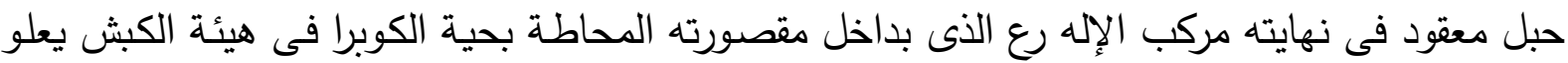

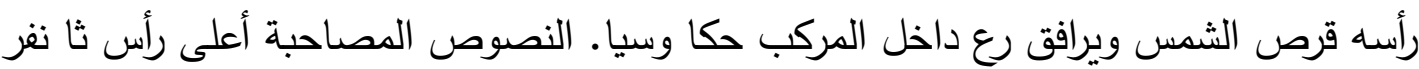
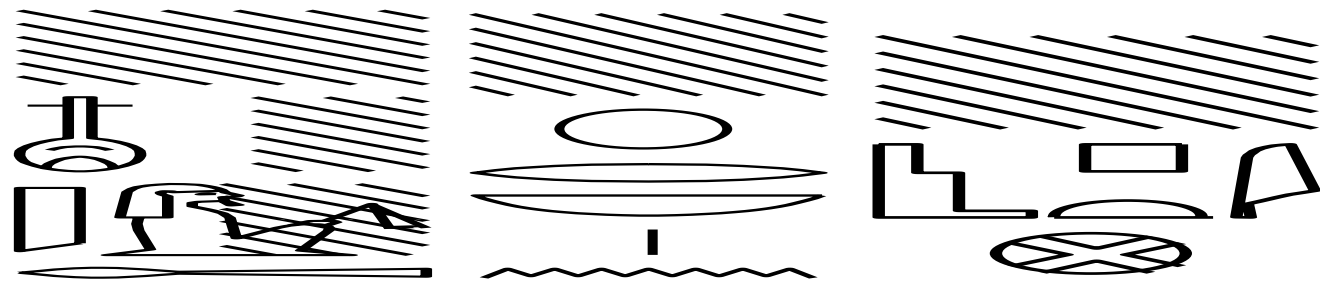

.Ipt - swt ........*A nfr $\widetilde{m A a}$ xrw ..........xr nb n

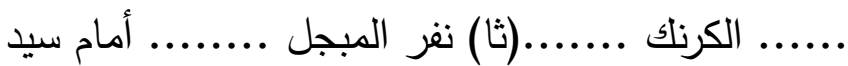




\begin{tabular}{|c|c|c|c|c|c|c|c|c|}
\hline 1 & $r$ & س & $\varepsilon$ & 0 & 7 & $V$ & $\wedge$ & 9 \\
\hline 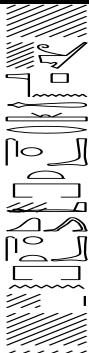 & "Wl, & 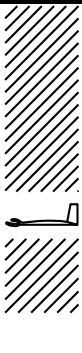 & 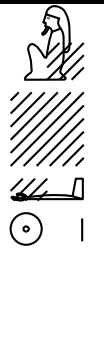 & 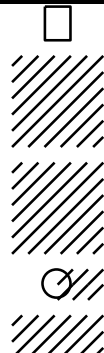 & 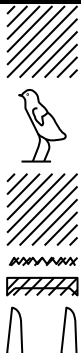 & $\begin{array}{l}\frac{\sqrt{n}}{0} \\
\sqrt{2} \\
\sqrt{2}\end{array}$ & 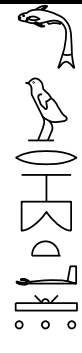 & 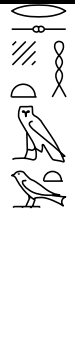 \\
\hline
\end{tabular}

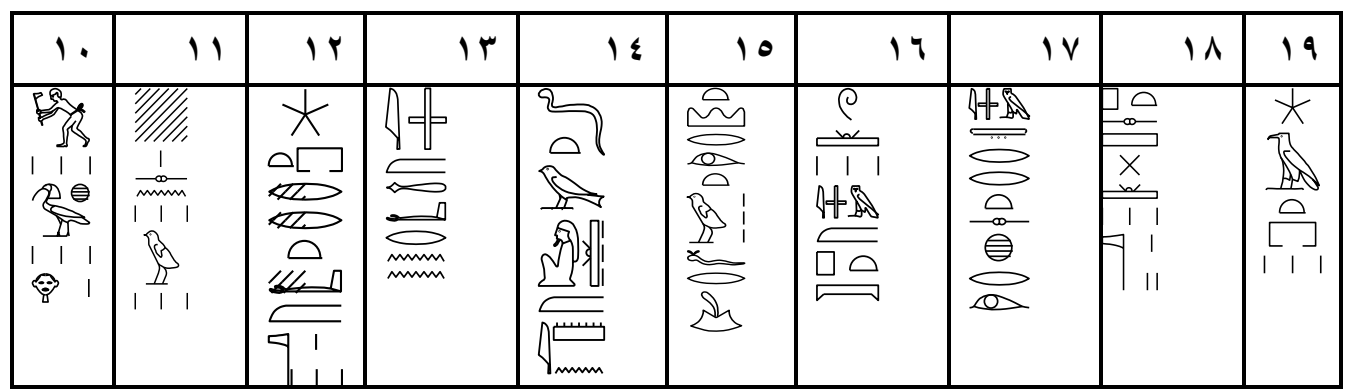

1-الوصول بواسطة هذا الإله العظيم إلي البوابة،

$$
\text { ودخول بوابة(ر) }
$$

r.............. r r...

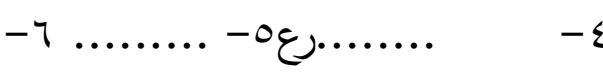

$$
\text { (توصيل) }
$$

$$
\text { - - Vميع - v }
$$

1-المدانين إلى المحاكمة

9- لتدمير جثث الأعداء

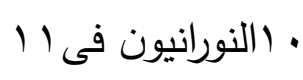

- أماكنهم (على عروشهم) وأولئك

r ا-الذين فى العـالم الآخر لكى يعطى الآلهـة ب ا -الذين هناك العظماء فى مقابل

$$
\text { § ا-الصغار فى الغرب }
$$

10-ولكى يجعل الذين (فى الغرب) يحكمون 1-[spr i]n nTr pn aA r sbxt aq sbxt $\mathrm{n}(\mathrm{Ra})$

2-[DbA].n.i

3-

4-. . $\mathrm{R}] \mathrm{a}$

$5-\mathrm{p}[\mathrm{w}]$ nkiyw

7- tm sA wr

8-XAtyw r wDat

9- r sHtm mt

10-Xftyw Axw Hr

11- [st].sn imyw

12- dwAt $r$ rdit m nTrw

13- imyw $\mathrm{m}$ aA $\mathrm{r}$

14- nDsw mimntt

15-r irt imyw.f r wDa

16- xrw imyw $\mathrm{m}$ pt

17- imyw m tA r irt sxr (r) irt

18- psSt nTrw 19-dwAtyw 
العـالم الآخـر يصـل عـددهم لســـ أشــخاص

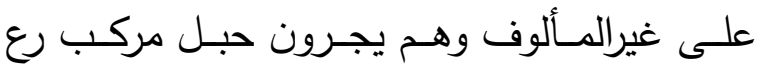

حيـث يقـوم الأثـخاص السـتة بســب مركب رع

التى يظهـر فـى منتصفهـا رع فى هيئة الكـبش

داخـل مقصــورة محاطـة بحيـة الكـوبرا ويرافتق رع

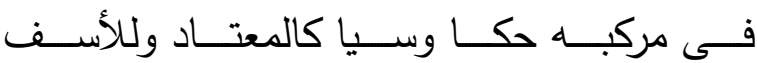

فــان النصـــوص المصـــاحبة مهثــمة بدرجــة

كبيـرة بحيـث لا يمكـن معهـا تكـوين جمـلا ذات معنى ويمكن فقط قراءة النص أعلى وجـه ثانفر

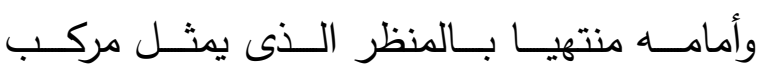
رع والملاحون بداخلها .النصوص المصاحبة اعلى

$$
\text { راس ثا نفر تبقي منها فقط : }
$$

[spr in nTr pn Wsir] Hm nTr n [Imn *A nfr mAa xrw r sbxt tn]

(الوصـول بواسـطة هـذا الإلـهـ وأوزير) كـاهن

(آمـون ثـانغر المبجل لهذه البوابـة) أمـام ثـا نفـر
7 ا 1 الذين فى السماء

IV

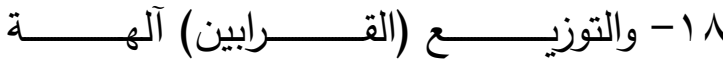
9 1-العالم الآخر (مقارنة بنصوص تابوت سيتى الأول أنظر: Piankoff and Maystre) 1939-1962,I, 304) المنظرالثالث الذى يمثل الساعة الثالثة من

كتاب البوابات (شكل •) يظهـر الجـزء الثانى مـن المنظـر ثـا نفـر متعبدا وأمامسه-على عكس بقية المنـاظر تظهر بوابـة الســاعة الثالثـة مزخرفـة بزخرفـة الغكــر ويحرسها من الأمام مومياوات على هيئة أوزيريـة وأمسام البوابـة مجموعـة مـن الآلهـة يمثلـون آلهـة

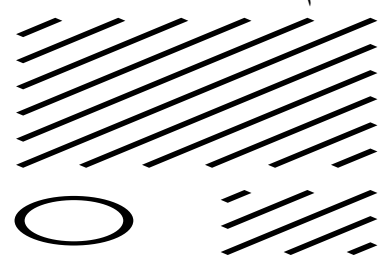

$$
\text { وأعلى مركب رع }
$$

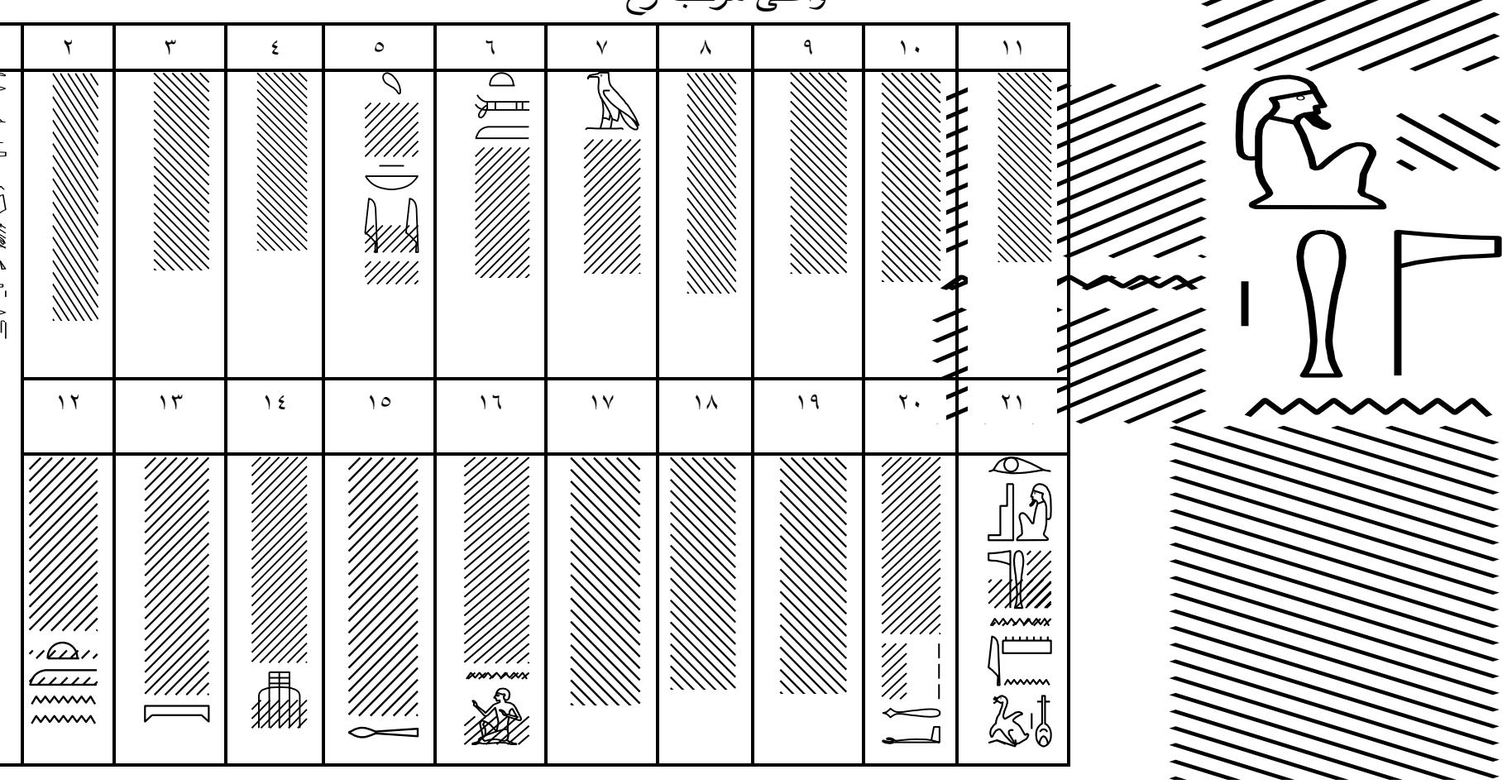


$-19$ IV . .7

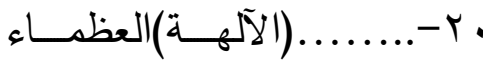

$$
\text { أوزير كاهن آمون ثا نغر }
$$

المنظر الرابع (الساعة الرابعة من كتاب البوابات)

(شكل ( )

يبدأ المنظر بثعبان ضخم حارس للبوابة التى

تتقدمـه والتى زخرفت بزخرفة الغكر ويحرسها من أعلى حيـة الكـوبرا ومـن الأمـام موميـاوات واقفـة ويظهرأمام البوابة ثا نفر يظهر منه ذراعيه وقدماه ويقـف متعبـدا وأمامـه زهـرة لـوتس وأمامـه يقـف مجموعة من خمسـة أشخاص يقومون بجر حبل مركب رع التى تظهر فى نهايـة المنظر بـداخلها الإلـه رع يصـحبه حكـا وسـيا ويقف رع فيى هيئة الكبش يعلو رأسـهـ قرص الشـمس داخل مقصـورة تحوطهـا مسن أعلـى حيـة الكـوبرا. النصــوص المصاحبة اعلى الملاحون ومركب رع 1-spr Wsir Hm nTr n Imn*A nfr mAa xrw nTr pn r sbxt
4-....

6-tm

$8-$

$10-$

$12-$

$14-$ tm 13-... $9-$ $7-$
$16-$

18

$20-$

21- Wsir Hm nTr n Imn *A nfr ا-وصول أوزيركاهن آمون ثا نفرالمبجلوالإله العظــيم لهــذه البوابــة -............. r-

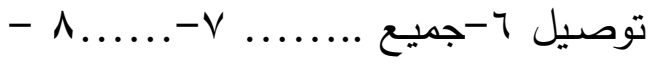
$-11 \ldots-1 \cdot \ldots . .-9 \ldots \ldots$ ..-1 r......... r|..........الســـاء ع 1... ..n.i $17-$ ...pt .xrW nikyw . 


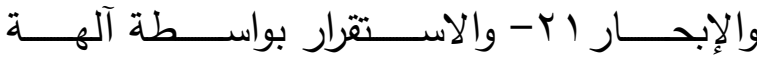

$10-$

n11-n.

النجوم/المادحين/آلهة الساعات

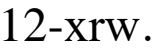

13 ink

14-........mAA......15-n.......16-

(Hornung 1979-1980, 255; Piankoff .....W.......n.....17

7.

...18-

sxrw 19-m pt s(b)i

r r- عند سحب هذا الإله العظيم rr-(على)

nTrw dwAtyw 20- sqdw 21- Htp in

طرقات العالم الآخر گ ؟ب-بواسطة جميع الآلهة.

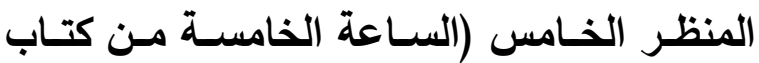
sbAyw 22- m sTA nTr pn aA 23[m]wAwt dwAt 24- in nTrw nbw

البوابات) (شكل V ل

تبدأ هذه الساعة بثعبان ضخم يحرس البوابة

I-الوصسول بواسطة هذا الإله - العظيم لهذه

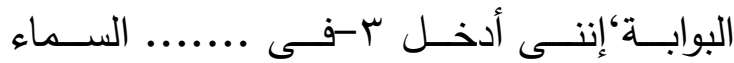

والأرضع -......... الوصـوله-..............

التى أمامها والتى تظهر بقايا زخرفة الغكر عليها وامسام البوابـة وقف ثـا نفر متعبدا وأمامـهـ مائـدة

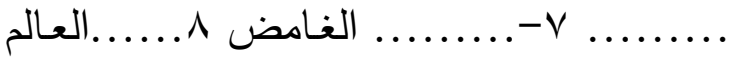
الآخــــــ............................ قرابين عليها إبريق ويعلوه زهرة اللوتس وأمسام ثا نفر يظهر جزء من قاعة المحاكمة التى هى أهم ما يميز السـاعة الخامسـة ويظهر فى المنظرالإلهـ

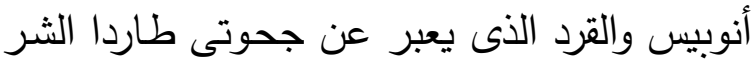

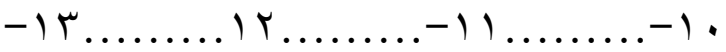

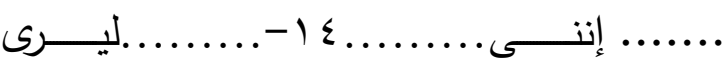
$-1 \vee \ldots . . .17 \ldots . . .10 \ldots \ldots$

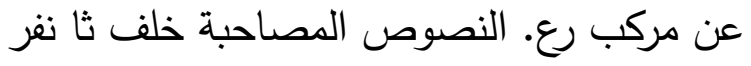

.

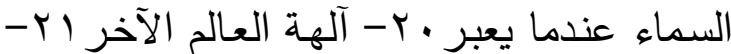

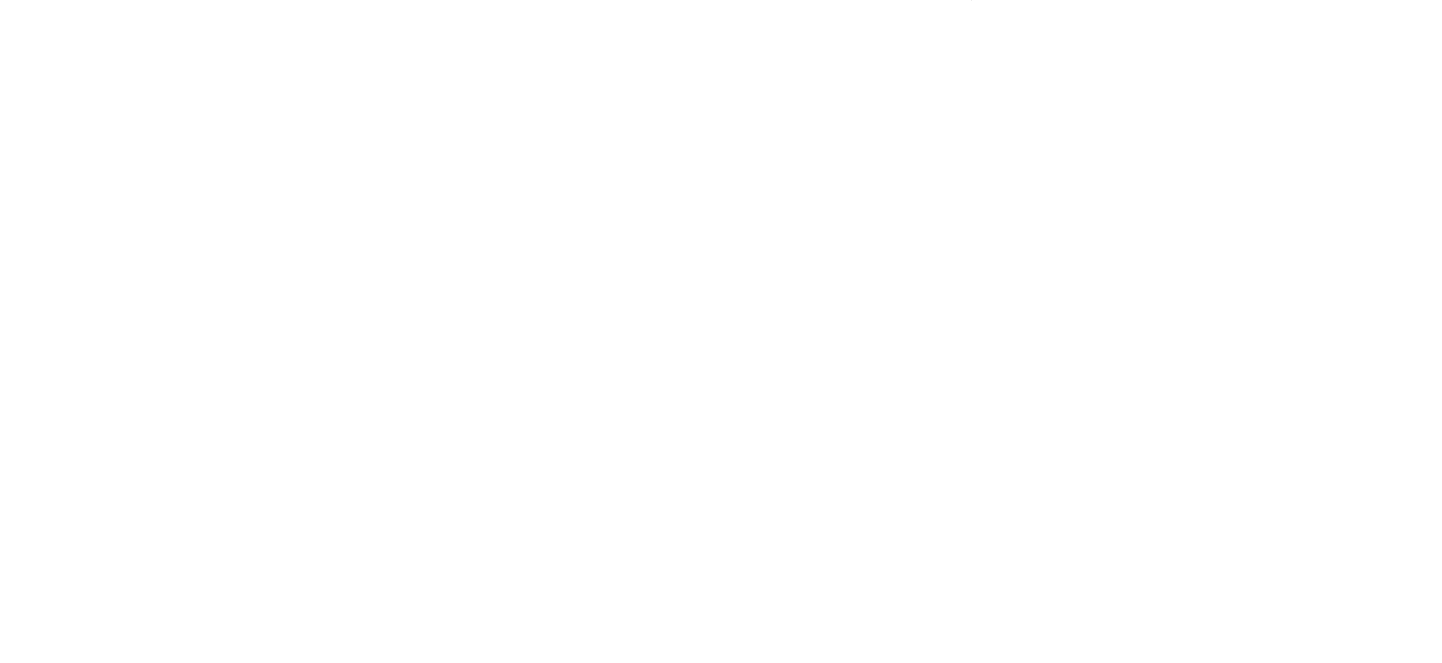

$\operatorname{spr}[$ in nTr aA pn] Wsir Hm nTr [n] Imn*A nfr mAa xrw

الوصول( بواسطة هذا الإله العظيم) وأوزير كاهن آمون ثا نفرالمبجل أمام ثا نفرواسفل أنوبيس 


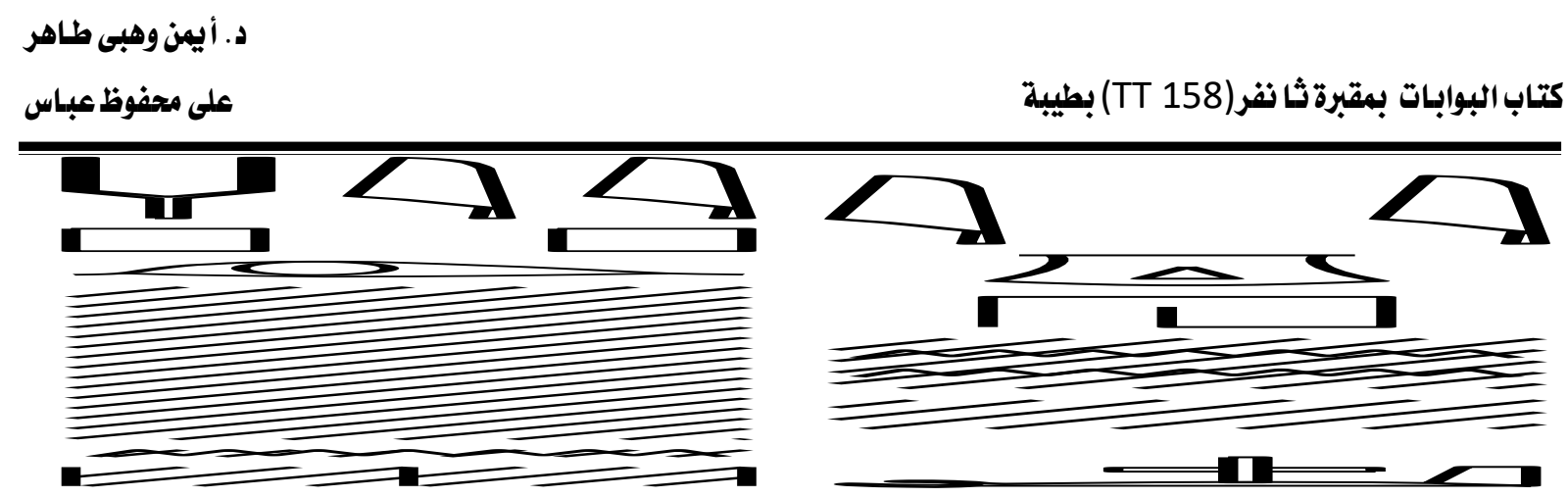

1-aHay ptr ......n 2- ky hnn[m] wDat

1-الناهض(أنوبيس) الذى يرى .

ץ-القرد الذى يبتهل فى قاعة المحكمة أمام القرد يوجد بقايا نص ومهشم تماما
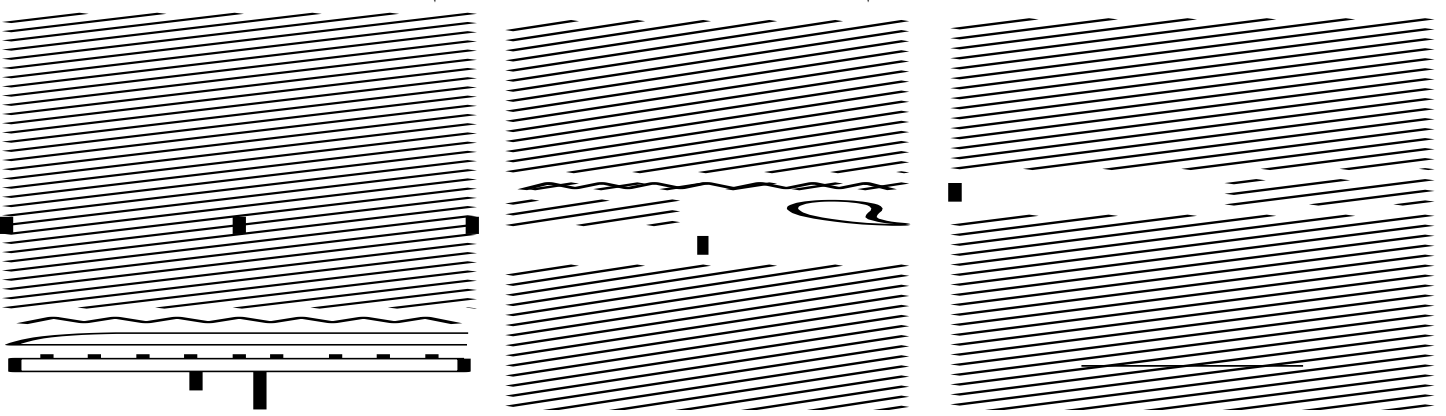

خلف القرد: يوجد بقايا نص ومهشم تماما

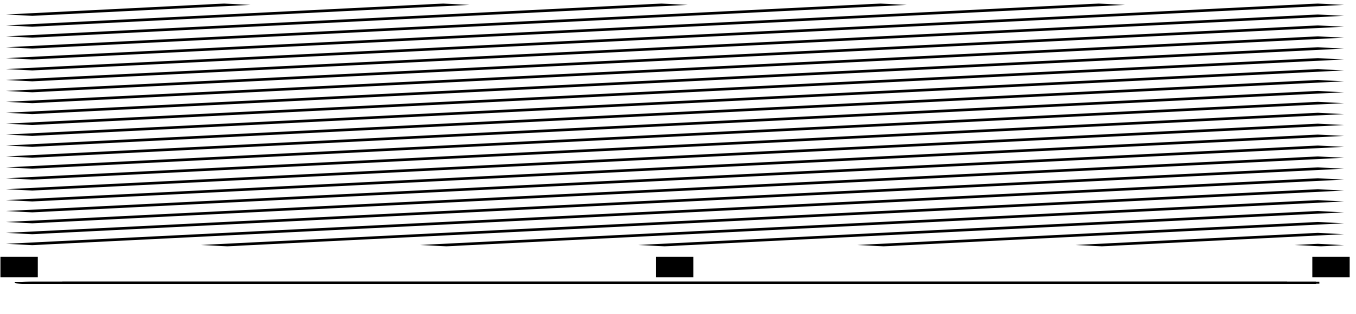

اسفل المركب من اليسار

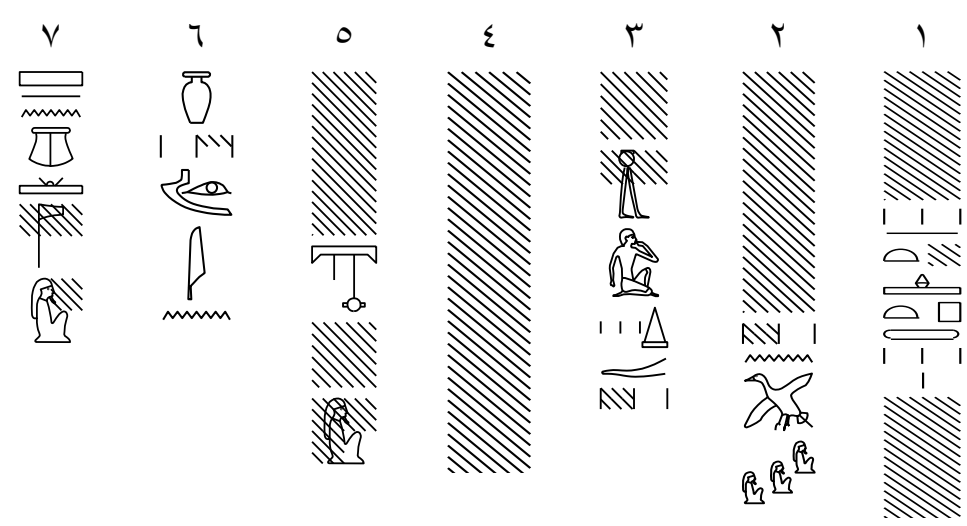

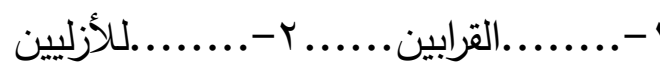

$1-\ldots . \ldots . .$. Htpw

$2-\ldots \ldots \ldots \ldots, n$ pAwtyw $3-[n T r]$ in

ب-(الإلها)|الذبحضرالميزان ع-................... mXAt $4-\ldots . . . . . . .5-. . . . . . . w b A . f$ kkw 6-smAw rnpw 7-m anx Htp -V $\mathrm{nTr}$ 
وبقايا بوابة يقوم بحراستها ـ النصوص المصاحبة أعلى رأس ثانفر
ثانيـا تصــوير كتــاب البوابـات علــى الجـــار الشمالي من الصالة الطولية: المنظـــالأول (الســـاعة السادســة مــن كتــاب البوابات) (شكل (^) يبدأ المنظر من اليسار بمركب رع التى زال معظمها ويجرهـا ثلاثـة مـن آلهـة العـالم الآخـر وأمامهر وقف ثا نفر متعبدا وخلفه ثعبان ضخم
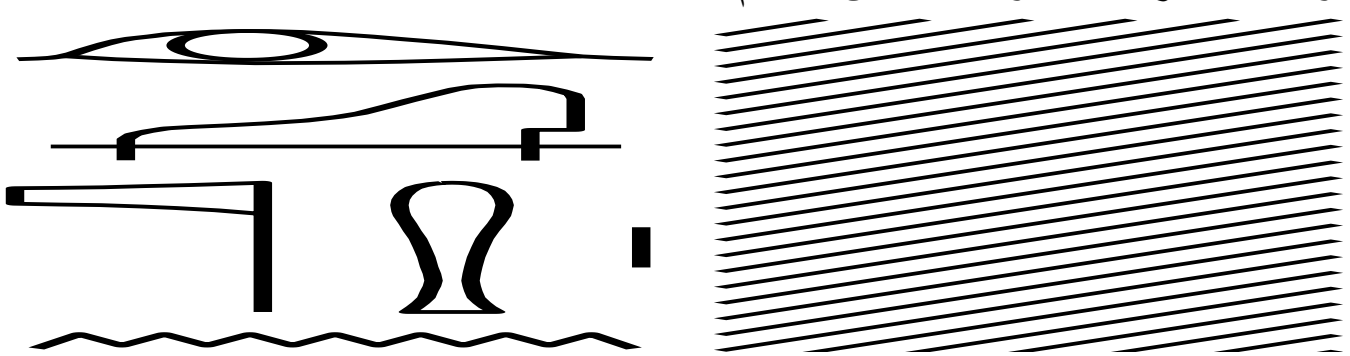

Wsir Hm nTr n 2- [Imn *A nfr mAa xrw] أوزير كاهن (آمون ثا نفر المبجل)أمام ثانفر واعلى مركب رع

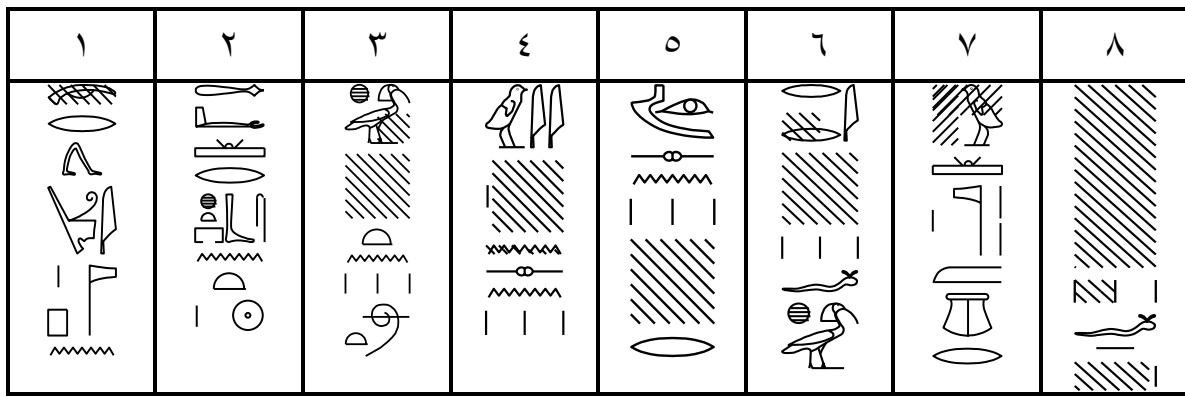

المنظرالثانى(الساعة السابعة من كتاب البوابات)

(شكل 9 (

خلف البوابـة يظهر الجزء الأول من السـاعة السابعة ويظهر هنا فقط الجزء الخلفى من مركب رع المهشمة بدرجة كبيرة ويظهر فـى نهايته مـن الناحية اليمنى بقايا البوابة التى يظهر فقط جزئها السفلى وبقايـا أقدام ربمـا تمثل فى الغالب ثا نفر وآلهة العـالم الآخر الذين يسـحبون مركب رع لــ يتبق منها سوي فقط نهاية الصف 1-spr in nTr pn 2-aA r sbxt nt Ra 3-Axw....... th sTAyw 4- .....n.sn 5-mAA.sn ..........r 6-ir (w).f Axw 7- nTrw m Xr(yw) 8-(mAat).f ا-الوصـول بواسطة هذا الإله ب- العظيم إلى الى بوابـة رع ب- والمبجلين ....... - المسـحوبين

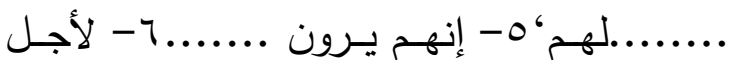
أثـكاله “والأبـرار V- والآلهــة فـى معيـة الآلهـة

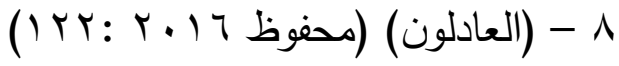




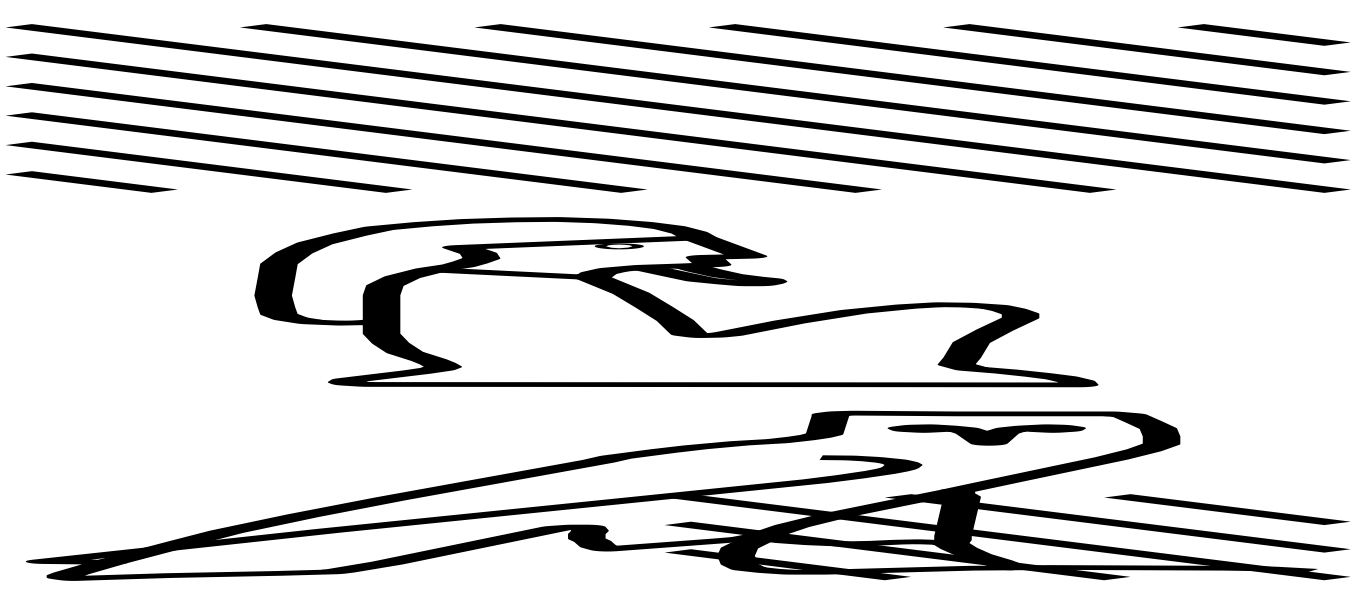

المنظر الثالث (الساعة الثامنة من كتاب البوابات وبداية الساعة التاسعة) (شكل 1)

وخلفه بوابـة يزينها زخرفة الغكر ويحرسـها حيتى

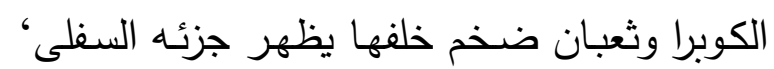

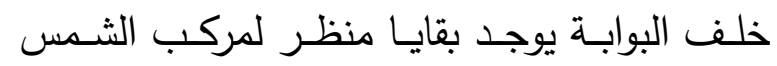
يظهر منها فقط المجداف أعلى رأس ثا نغر
يبـدأ المنظـر ببقايـا مركب الثـمس وهـى مهشمة بدرجة كبيرة وأمامها وقف أربعة من آلهة

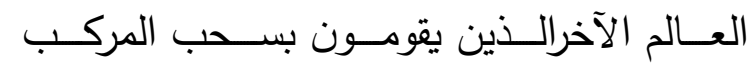

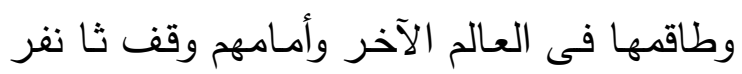
متعبدا مرتديا زى الكهنوت متمثلا فى جلد الفهد
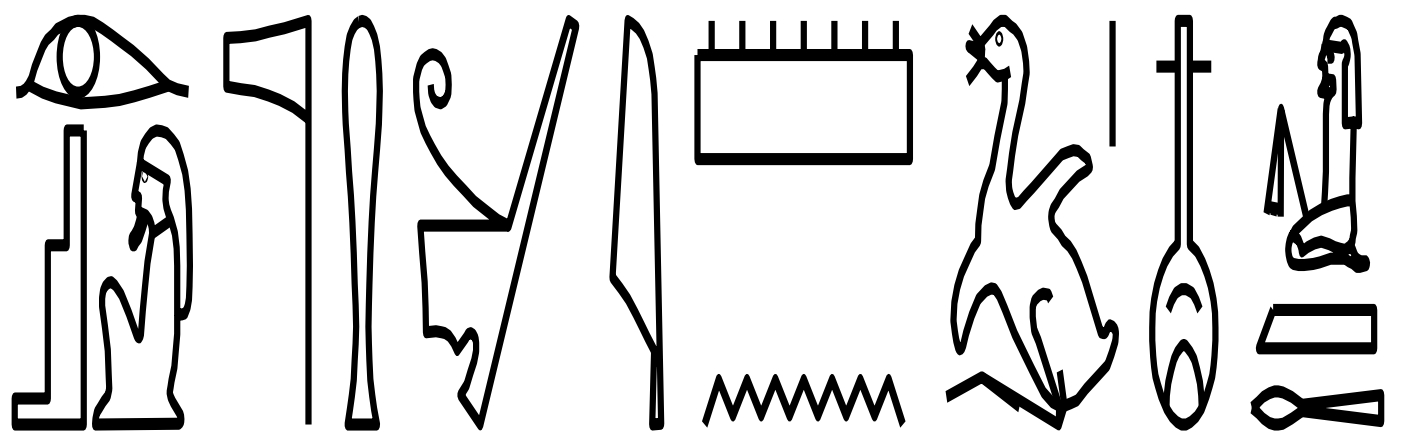

Wsir Hm nTr n Imn *A nfr أوزير كاهن آمون ثا نفرأمام ثا نفر وفوق مركب الثمس

\begin{tabular}{|c|c|c|c|c|c|c|c|c|c|}
\hline 1. & 9 & $\wedge$ & V & 7 & 0 & $\varepsilon$ & $r$ & r & 1 \\
\hline 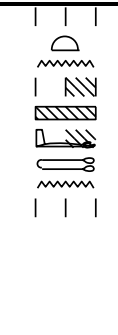 & & & 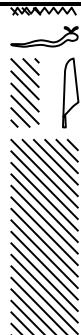 & 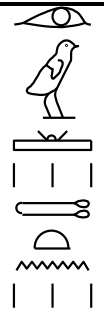 & 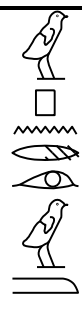 & 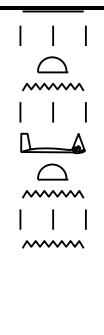 & 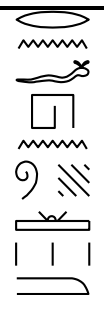 & 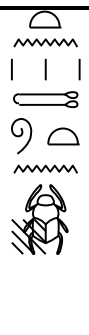 & 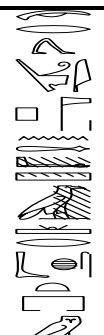 \\
\hline
\end{tabular}

4- tAw.Tn di.Tn 5- StAw n irw m

1-spr in $n \operatorname{Tr}$ pn aA r sbxt m tAwy $r$ 2- Tn Twt n xpr 3- n.f hnw m 
المنظر يمثل بقيـة السـاعة التاسـعة وفيها

يظهر أحد آلهـة العـالم الآخـر ويظهر فـى يـده نهاية طرف الحبل المربوط بمركب رع ويظهر أمامه فى الغالب ثا نفر متعبدا وأمامه بقايا مائدة قرابين .معظم النصوص مهشمه ومفقودة وتبقي

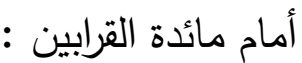

6-irw.Tn 7-n.f ..... 8-

10- tn mAa(t).tn

1-الوصول بواسطة هذا الإله العظيم للبوابة فى الأرضين ب-لأجلكم أنتم لتجعلوا الإبتهاج ب يحدث لأجلـه فى ع-أراضـيكم إنكم تجعلون 0-الأشكال الغامضة بين ؟-هيئاتكم

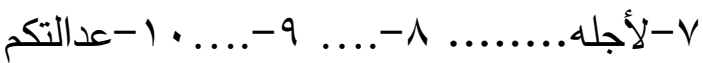
المنظر الثالث(بقية الساعة التاسعة من كتاب

البوابات) (شكل 1 (1) - (1)

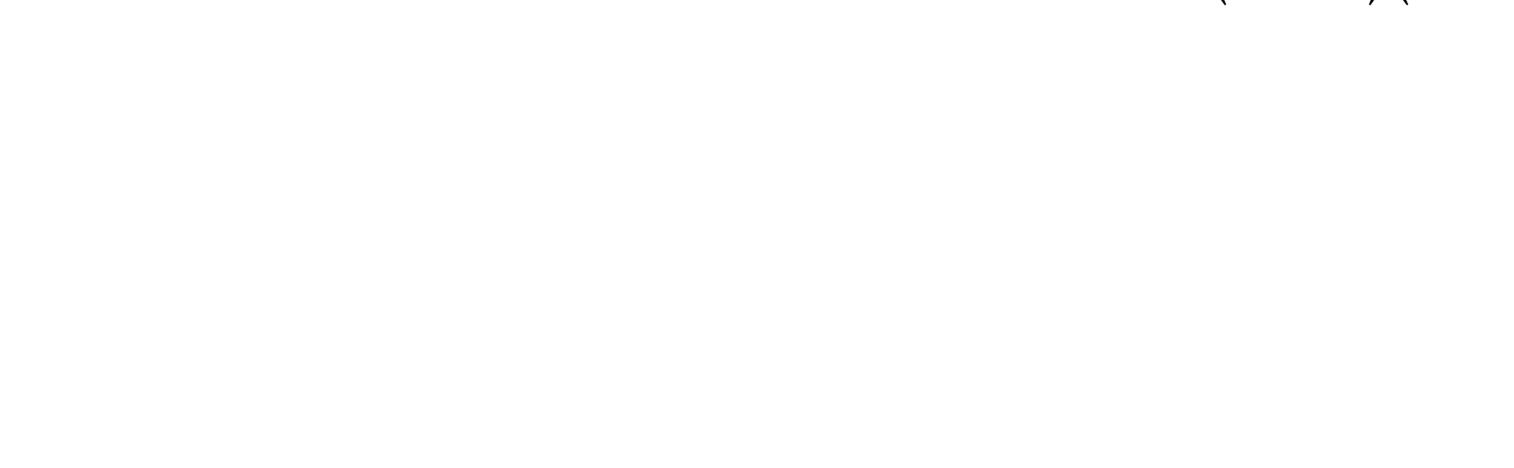

spr [in nTr pn aA r sbxt] Wsir Hm nTr n Imn *A nfr

والآلهة المرافقة ، يقف ثا نفر فى المواجهة متعبدا وخلفه تظهر البوابة المزينة بزخارف الغكر وآلهة على هيئة المومياوات وخلف البوابة ثعبان ضخم

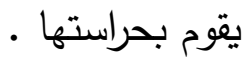

يشتمل الجزء الأخير من المنظر على بقايا الجزء الأول من الساعة الحادية عشر ويظهر فيه بقايـا مركب الشـمس وببدو منـه فقط المجداف.

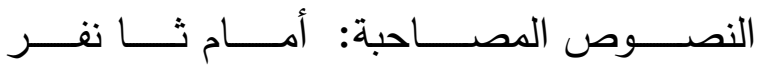

الوصول (بواسطة هذا الإله العظيم ) إلى البوابة وأوزير كاهن آمون ثا نفر المنظرالرابع (الساعة العاشرة من كتاب البوابات وبداية الساعة الحادية عشر) (شكل r Y ) يظهر فـى المنظـر إلهين مـن آلهـة العـالم الآخر أحدهما بـرأس على هيئة ثعبانين ويقوم الإلهان بسكب المياه وخلفهمـا جزء مهشـ كـان مـن المفترض ان يشـتمل على مركب الشـمس

\begin{tabular}{|l|l|l|l|l|l|l|}
\hline & $r$ & $r$ & $\varepsilon$ & 0 & $r$ & $V$ \\
\hline
\end{tabular}




\begin{tabular}{|c|c|c|c|c|c|c|}
\hline 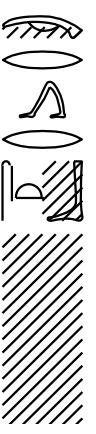 & 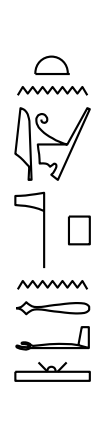 & 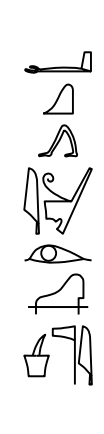 & $\underbrace{\infty}_{\mathbb{U} / / /,}$ & 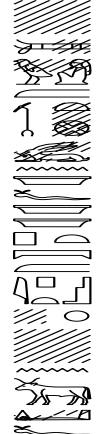 & I & 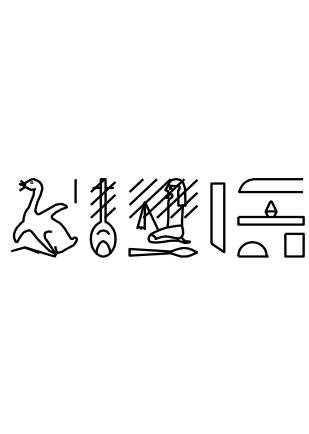 \\
\hline
\end{tabular}

كبيرالرائين لرع 0-آتوم فى طيبة فاتح أبواب

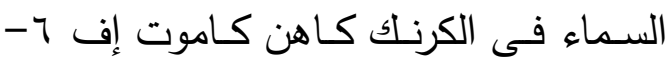
كاهن آمـون V- ثا نفر المبجل فى سـلام وباقي النص أعلى الآلهة

1-spr r sbxt [aq sbxt] 2-tn in nTr pn aA 3- aq in Wsir it nTr 4-wab awy wr mAAw $n$ Ra 5- \&m m WAst wn.f awy pt m Ipt-swt [Hm nTr] n KA-mwt.f 6- Hm nTr n Imn 7-*A nfr mAa xrw m Htp

ا-الوصـول إلى البوابـة دخول ب-هذه البوابـة

بواسـطة هــا الإلــهـه العظـيم ب-والــخول

بواسـة أوزيـرالأب الإلهى ع - مطهراليدين

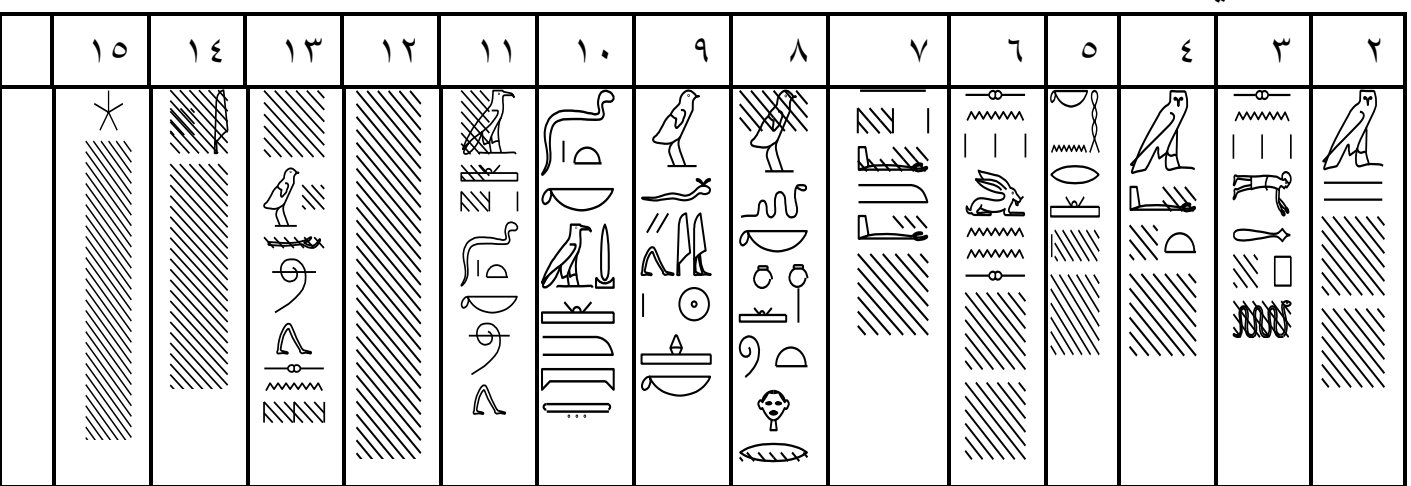

تسـتقر • 1- ويعبر جسـك السـماء والأرض ||الحمايـة لجسـك عند سـب r ا -...................

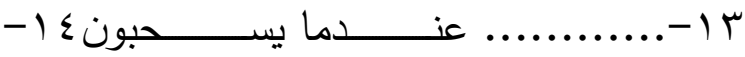

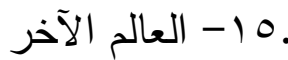
المنظرالخامس(بقية/الساعة الحادية عشرمن كتاب

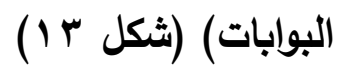
يمثل بقية المناظر الخاصـة بالسـاعة الحادية عشر رغم التهشم الذى تعرض لله هذا الجزء من المقبرة ، يبدأ المنظر بإلهين من آلهة العالم الآخر

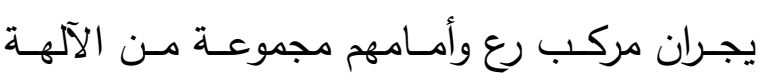

1-rdit ........2- m tAwy ...... 3-.sn xr aApp 4-m dit.....5- Hkn(.sn)(m sbAw) 6- .sn wnn .sn m sxrw 7- aHa 8- iarwt.k inD.tw Hrw 9- f ii Ra Htp.k 10- Dt.k DA m pt tA 11- sAw Dt.k sTA $12-\ldots . . . . . . .13-\ldots . . . . . .$. sTA.sn $14-\ldots . .15$ dwAt...........

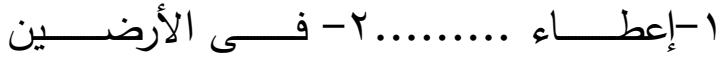
. r....... 0-إنهم يمدحون (مع نجومهم) - - إنهم يوجدون بالتعاويذ V- فلتنهض م-حيات الكوبرا خاصتلك

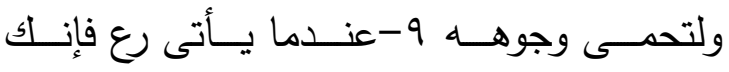




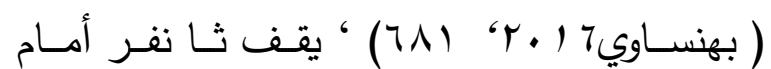

هؤلاء الآلهة حليق الرأس متعبدا فى زيـه الكهنوتى الكي

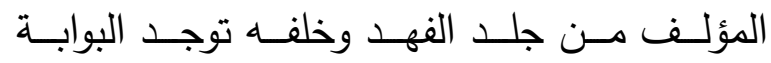

التـى زخرفـت بزخرفــة الغكــر ويحرسـها حيتــا

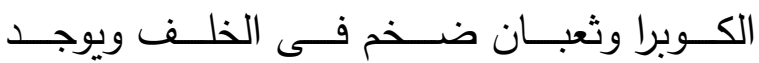

فى منتصف البوابة صولجانى الواس تعلوهما رأس

آدميـة وبينهـا نـص كتابى ويعــــــــا التجسـيد

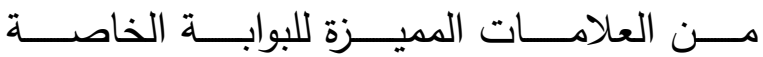

بالساعة الحادية عشر النصوص أعلى آلهة العال

الآخر وأمام وجه ثا نفر

\begin{tabular}{|c|c|c|c|c|c|c|c|c|c|c|c|c|c|}
\hline $1 \varepsilon$ & 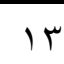 & IT & 11 & 1. & 9 & $\wedge$ & $\mathrm{v}$ & 7 & 0 & $\varepsilon$ & $r$ & 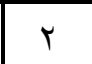 & 1 \\
\hline $\begin{array}{l}w^{1} \\
\mathbb{w}^{\prime} \\
\mathbb{w}^{\prime}\end{array}$ & & 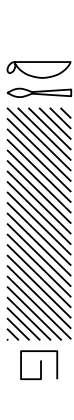 & $\stackrel{1}{W}$ & & 武 & 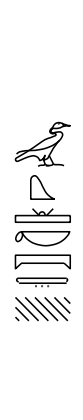 & 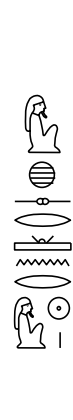 & 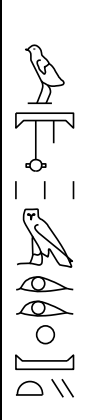 & 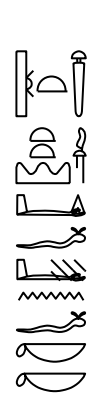 & 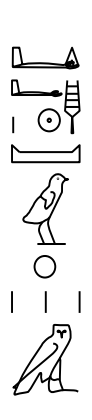 & 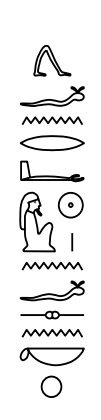 & 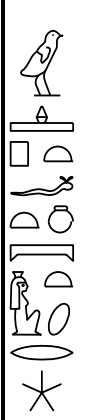 & 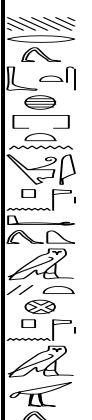 \\
\hline
\end{tabular}

\begin{tabular}{|c|c|c|}
\hline$r V$ & דצ & \\
\hline שே & <辵 & \\
\hline & $1 \%$ & \\
\hline 0202 & $\overrightarrow{\partial y}$ & \\
\hline 这 & קh & \\
\hline & & \\
\hline
\end{tabular}

13-hrw $\mathrm{Hm}$

15-Sms......16-sTA.snhrw

17-TAnTrw18-...19....20.....

21-.......22-[HtpdwAtywimyw

23-[dwAtsprr sbxt tn in nTr pn 24- aA aq in 25-Wsir it nTr wab awy

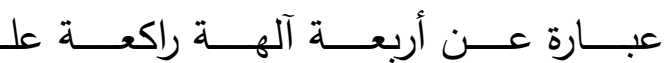

هيئة مومياء، وجميعهم على رؤوسهم حية كوبرا،

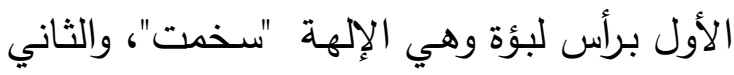
برأس بتاح ويطلق عليه "الذي يغرق"، والثالث

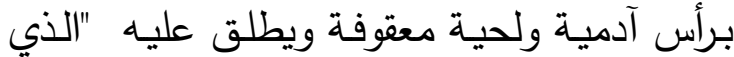
يتنس"، والرابع والأخير وهو برأس صقر ويطلق عليه "حور" (Hornung 1979-1980, 253) ولم تُكتب أسماء هؤلاء الآلهة فى هذا المنظر وكانت وظيفتهم حراسة الصورة الخفية للإله التي هلي لا يراهـا أحـد عندما يكسون في العـالم السـفلي

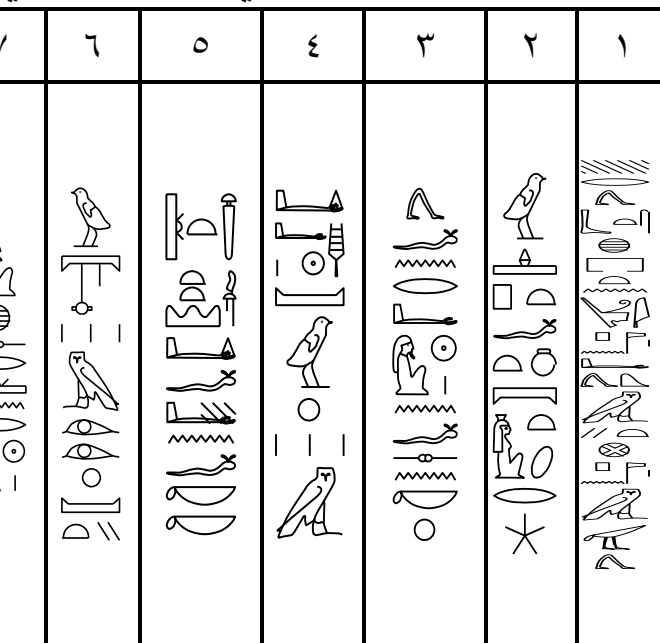

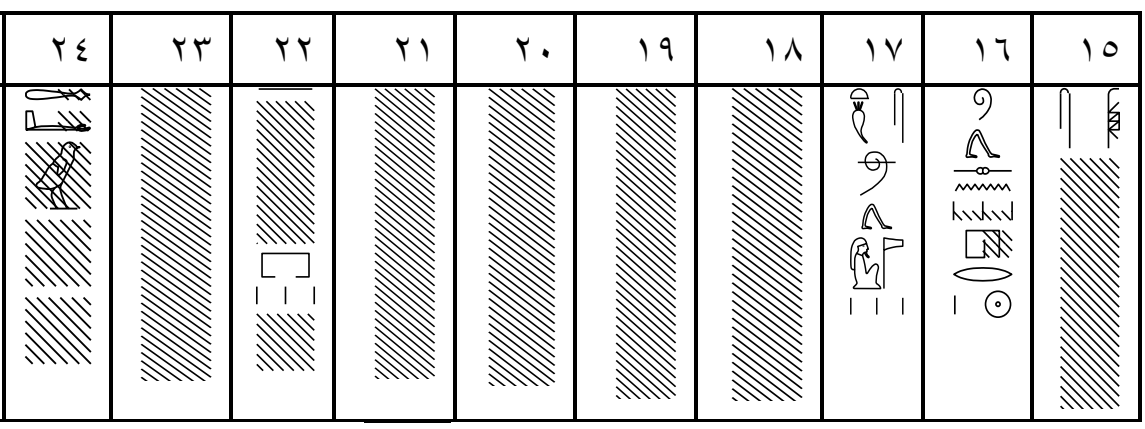

$\mathrm{pt}$

1-(sp)r[r]sbxt tn in nTr pn aq m niwt nTr pn m sSmw 2- Htp.f [m Xt] Nwt r sbi 3-.f n Ra [m] snk 4- di aHa Ra [m] Dww m 5-tpyt imntt di.f ak.f kkw 6-m Axty 7-sxr? n Ra 8-aq.k pt tA..9-wn.........10-. 11-tp.k 12-n.kxrw 
د. أيمن وهبى طاهر

على محفوظ عباس

كتاب البوابـات بمقبرة ثا نقر(TT 158) بطيبة

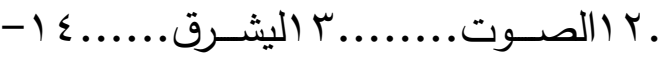

26-wr mAAw $\mathrm{n}$ Ra m WAst Hm

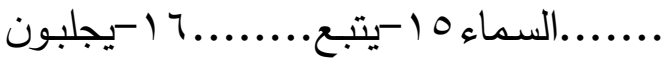
nTr27-n Imn*A nfr mAa xrw m Htp

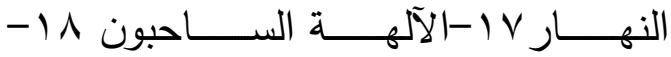
1-"الوصول إلي هذه البوابة بواسطة هذا الإله

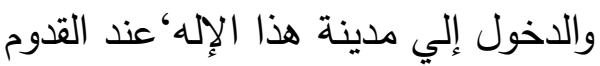

ب- بيستقر (رع) فى داخل نـوت عندما يدخل

(WbIII,429,10-431,28)

الآخر فى العالم الآخرعند بr-آبالوصول إلى الى

البوابة بواسطة هذا الإله العظيم ع كوالدخول

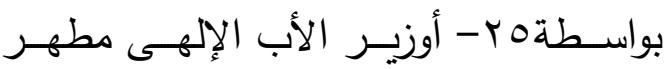
اليدين جr-كبير الرائيين لرع فى طيبة كاهن

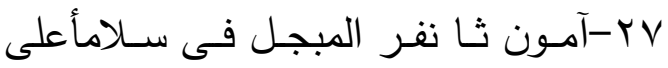
رأس ثا نفر

\section{(Whill,}

(Wb IV, 179,4-10) ك-رع الظـلام) ع -ليته يجعل رع ينهض(فى) الجبال التى

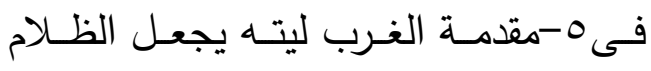

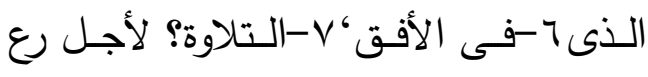

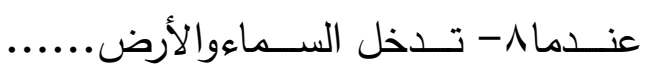

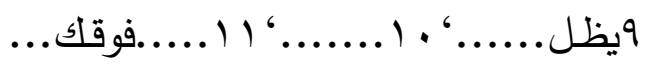

(2)

1-Wsir wr mAAw n 2-Ra m WAst 3-Hm nTr n Imn 4-*A nfr mAa xrw ا-أوزيركبير الرائيين - لرع فى واست

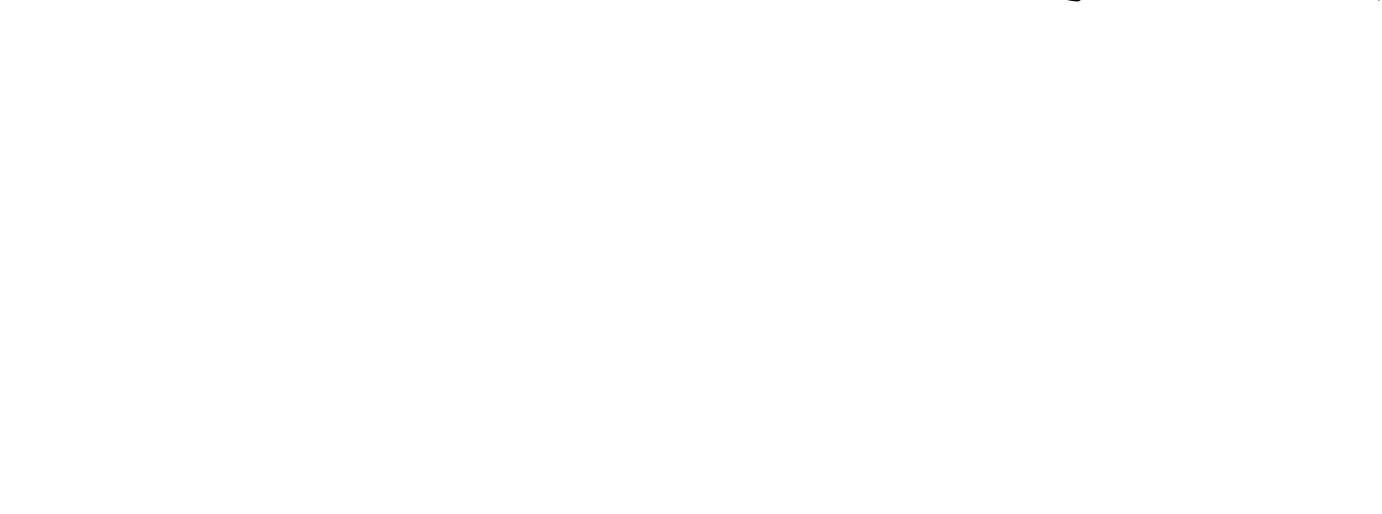

in .sn n Ra m Htp m Htp المنظر الخامس(الساعة الثانيةعشر من كتاب (البوابات) (شكل \& 1 ( )

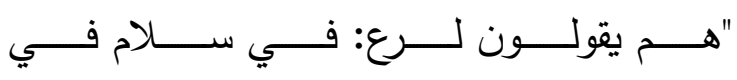
(Hornung 1979-1980,265; ســام Zandee1969, 320) 
يظهر فى بدايـة المنظر بقايـا مركب رع

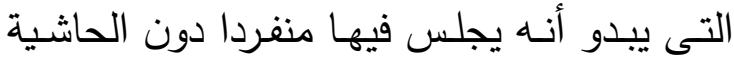

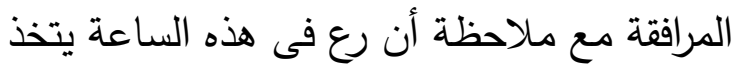

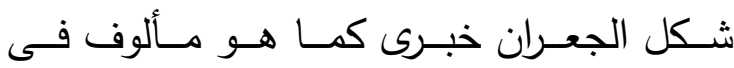

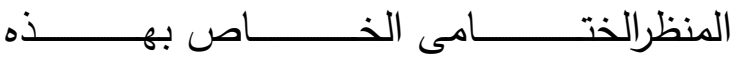

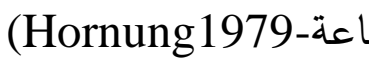
الس

1980,268;Zandee1969,323; Piankoff (1954, 223) وأمامهم يظهر فقط جزء من ذراع ثا نفر متعبدا

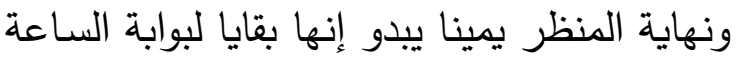

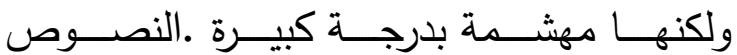
المصاحبة :أمام ثا نفر وأعلى آلهة العالم الآخر

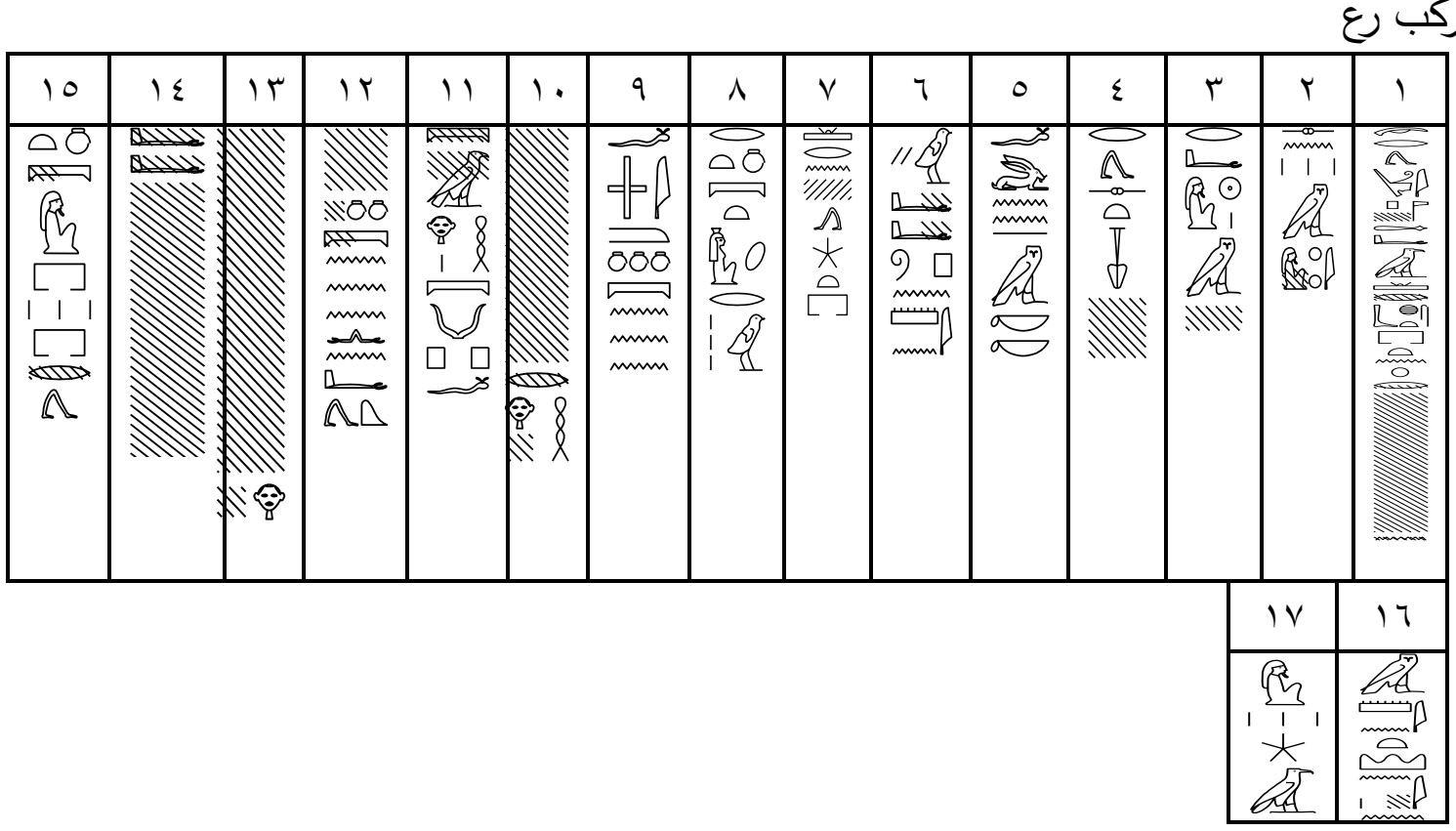

15-Nwt dwAtyw 16-pr(w) m imntt in 17-nTrw dwAt

1-"الوصول بواسطة هذا الإله العظيم إلي هذه

البوابة بواسطة فى معية(آلهة العالم الآخر r- الإله هاهي

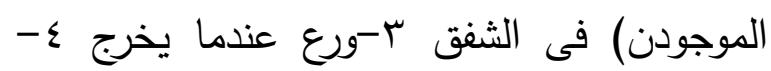

بهيئته البدائيةه-ويظل فى ذلك الظلامج- الخفى 1-spr in $\mathrm{nTr}$ pn aA $\mathrm{r}$ sbxt th $\mathrm{xr}$ [nTrw dwAtyw wnn] 2- .sn m ixxw 3- Ra m pr 4-st smAw.5-f wnn(.f) m kkw 6- pw n imn 7-r Pr [m] dwAt 8-[m] Nwt irw 9-.f imy m Nwn10....... r Hryw ... 11-m Hryt wp.f 12-[dwAt] r Nwn nn aq 13-[nTr pn Hryt irt xpr Hr] 14- awy [nwn imy] 
بمعبد آمون رع بالكرنك وكذا زوجته حفيدة

الكاهن الأكبر لآمون باك إن خنسو .

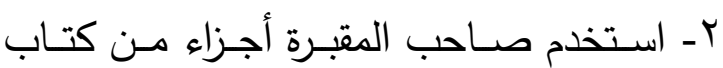

البوابـات تمثلت فى موكب إلـ الثـمس رع

وكـذا البوابـات التـى تمثـل ســاعات الليـلـ

الاثثتـي عشـر التـى كـان على المتـوفى أن

يجتازهـا بعد معرفة اسماء البوابات وحراسها

ليعبر من خلالها للعالم الآخر ويرافق رع فى

رحلته فى العالم السفلى ويضمن ان يولا من

جديد مع شروق الشمس صبيحة كل يوم.

r- التغيير الدائم في عدد الآلهة التى تسحب

إله الشمس فمن المعروف أنهح أربعة آلهة

لكن هنا في هذه المقبرة تتوعت مابين ثلاثثة

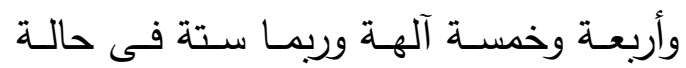

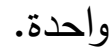

ع- تـم تصـــوير الســاعات الخمـس الخاصــة

بالبوابات على الجدار الجنوبى ثم استكملت باقى البوابات من السادسة حتى الثانية عشر

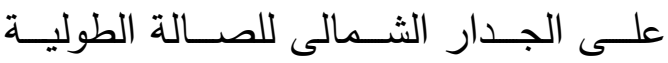

المؤدية للمقصورة وحجرة الدفن.

0- تتـاول النصوص المصـاحبة وصسول موكب

الشمس متمثل فى الإله رع والآلهة المرافقين

الذين يقومسون بوظيفة سـب المركب وكذا

تـأمين مسـار مركب الشـمس مـن مخـاطر

العالم السفلى ويظهر صـاحب المقبرة متعبداً

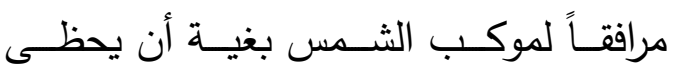

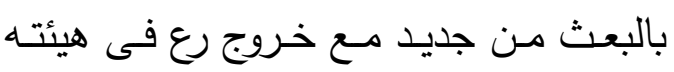

خبرى صبيحة كل يوم .
V- ليخرج من العالم الآخر 1-من نوت، و-

وأشكاله التى فى المحيط الأزلى. 1- لأجل

هؤلاء ||- الذين فى السماء ويفصل بين ||العالم الآخر المقابل للمحيط الأزلى عندما يدخلسا-هذا الإله السماء بينما تتحول الأشكال ع ا-على يدى نونه ا-الذى فى السماء وآلهة العالم الآخر 17 آ يخرجون من الغرب عندما تقول V ا - آلهة العالم الآخر. وبهذا المنظر ينتهي تصوير كتاب البوابات

على هذه المقبرة.

النتائج

1 - تعد هذه المقبرة هي المقبرة الوحيدة -حتى

الآن - مـن مقـابر الأفراد المصـور عليهـا

نسـخة مـن كتـاب البوابـات التى تمثـل

الاثتتي عشرساعة في عصرالدولة الحديثة

حيـث كـان الملـوك لا يسـمحون للأفـراد

بتصـوير كتـاب البوابـات على مقــابرهم،

ونظـراً لعلـو شـأن كهنـة آمـون في نهايـة

عصـر الدولـة الحديثـة وسـيطرتهم على

الحكــم بعــد ذلــك فـي الأســرة الحاديــة

والعشرين كان سببا لتمكين الكاهن الثالث

لآمـون (وربمـا صـار الكـاهن الأول قبيـل

وفاته) أن يستخدم أجزاء من كتاب البوابات

في مقبرته، وظهر ذلك بظهور الكاهن في

استقبال مركب إله الشمس في كل المناظر

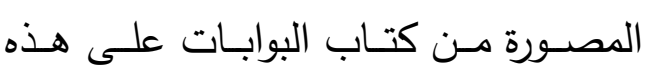

المقبـرة' مـع الأخذ فـى الإعتبـار أن هـا

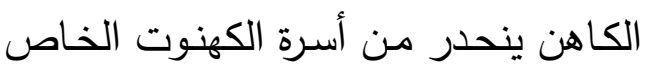

المناظر والأثنكال 


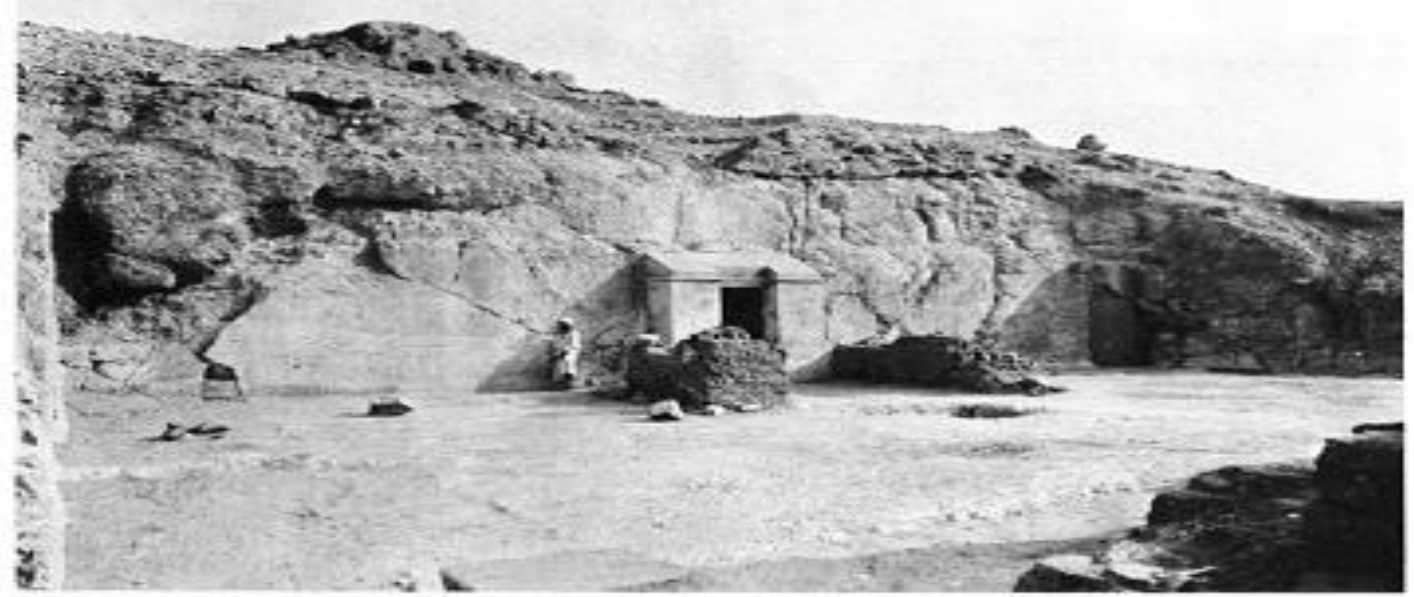

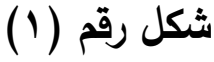

Seele 1959, pl.11 واجهة مقبرة ثا نفر نقلا عن

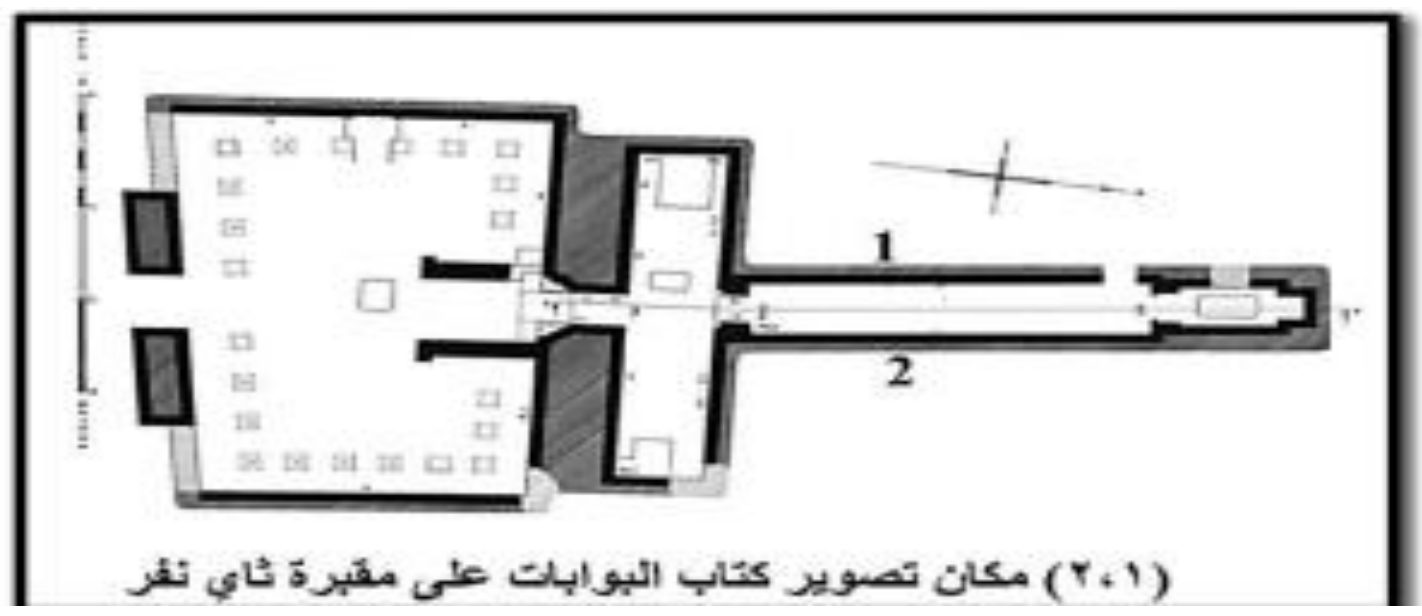

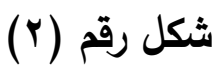

Seele 1959, pl.41 تخطيط مقبرة ثا نفر نقلا عن

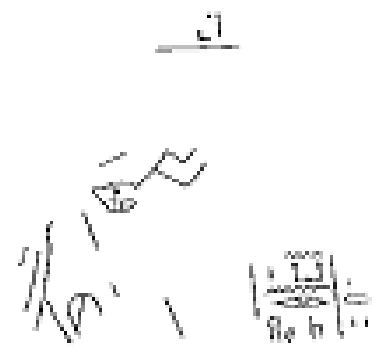

in

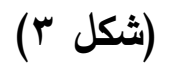

Seele 1958, pl.33 المنظر الأول (الساعة الأولى من كتاب البوابات) نقلا عن الباتل 

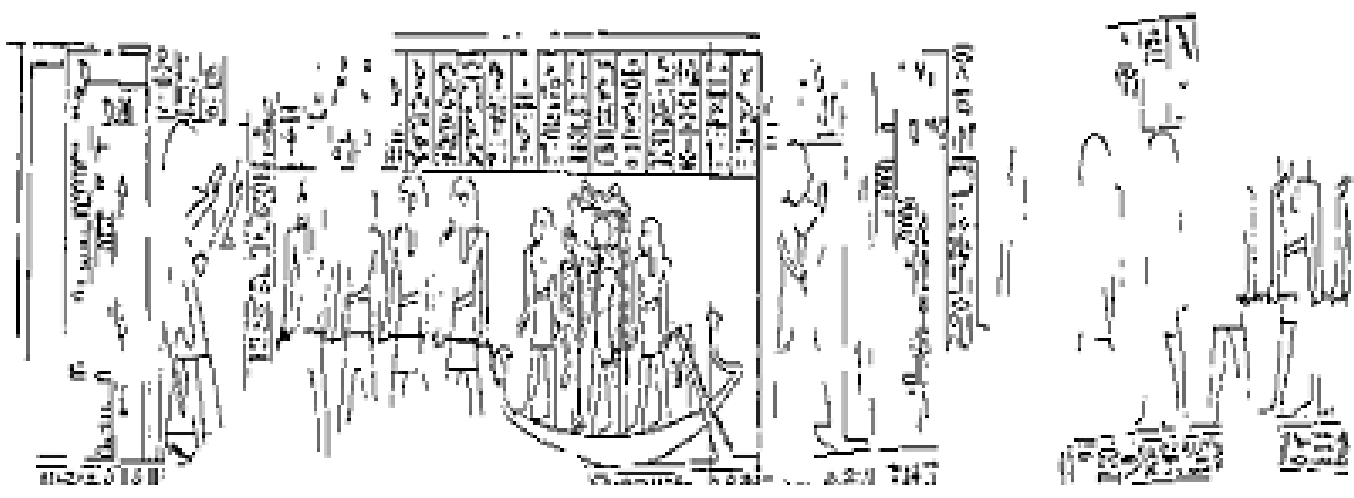

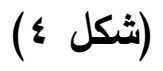

Seele المنظر الثانى (الساعة الثانية من كتاب البوابات وباية الساعة الثالثة) نقلا عن:

\section{9:pl.32}
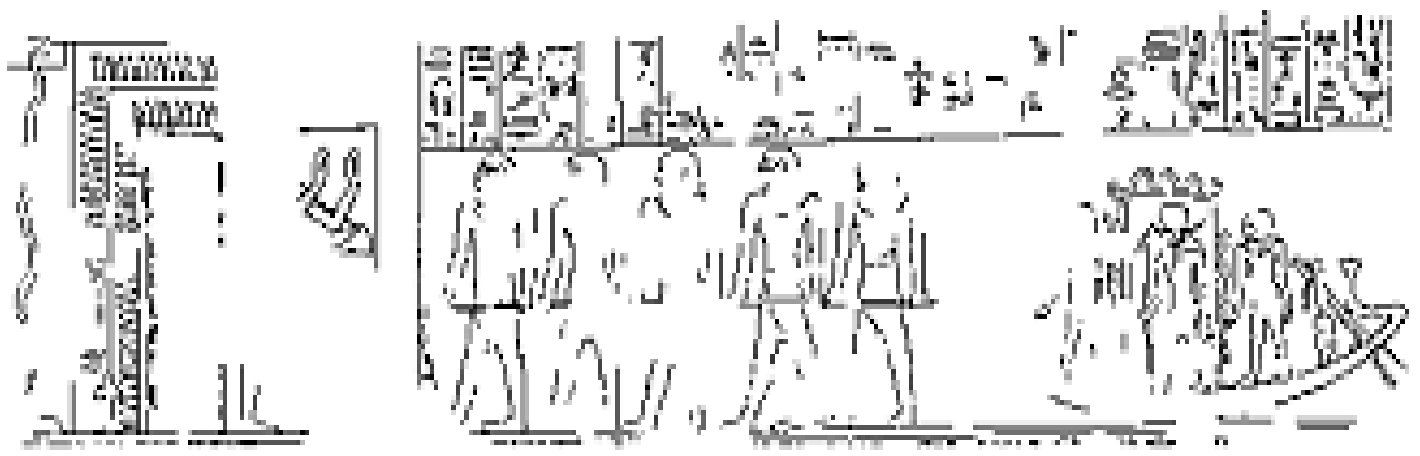

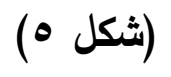

Seele 1959, pls.31-32:المنظر الثالث (الساعة الثالثة من كتاب البوابات).نقلا عن هن

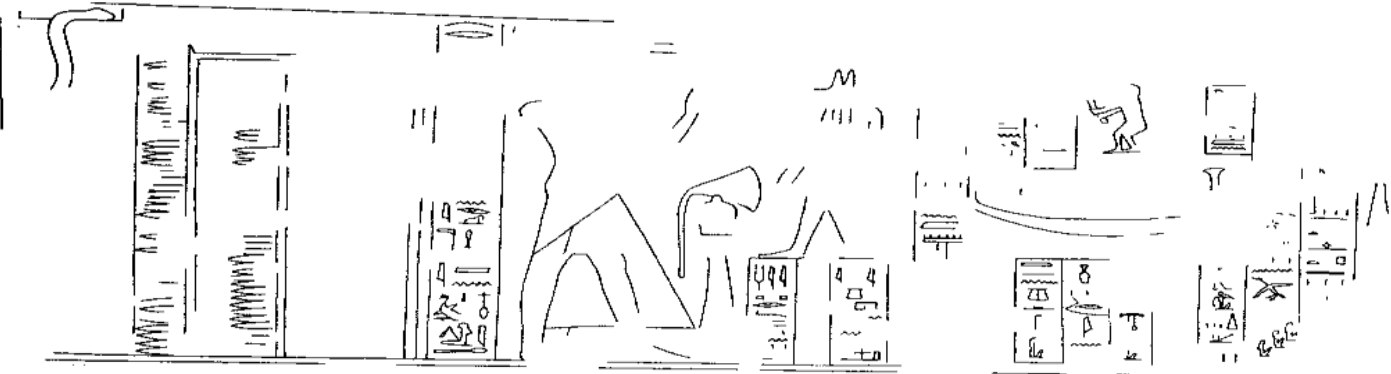

(شكل

Seele 1959, pl.31:المنظر الرابع (الساعة الرابعة من كتاب البوابات) نقلا عن 


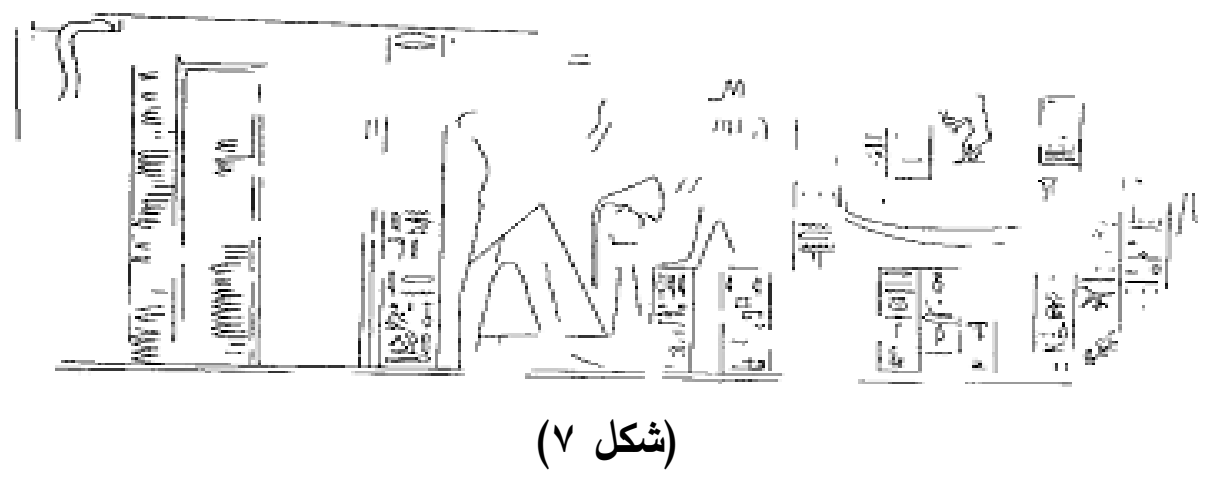

المنظر الخامس (الساعة الخامسة من كتاب البوابات) نقلا عن:Seele 1959, pl.30

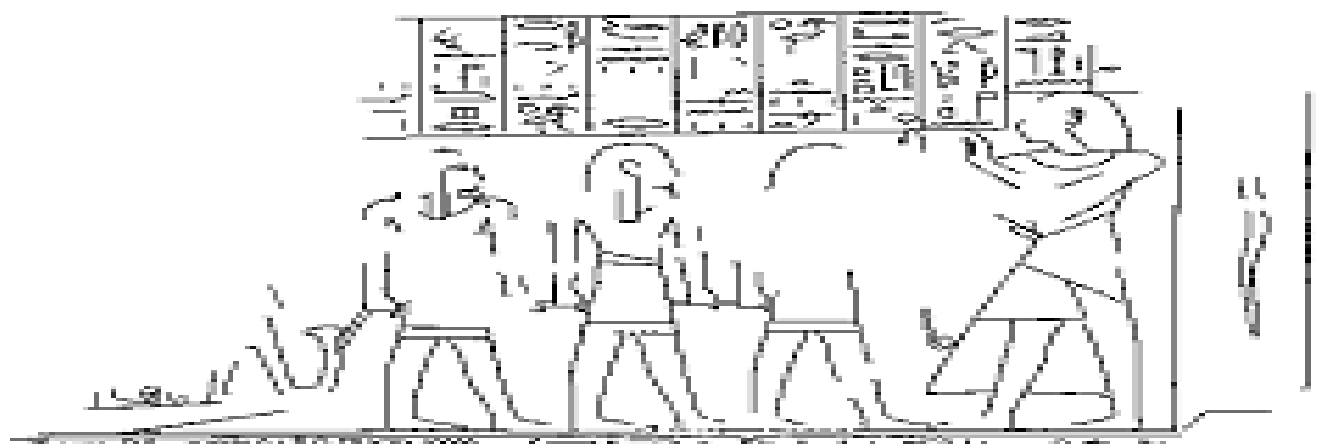

(شكل^)

المنظر الأول (الساعة السادسة كتاب البوابات على الجدار الشمالي من الصالة الطولية: نقلا عن Seele 1959, pl.38
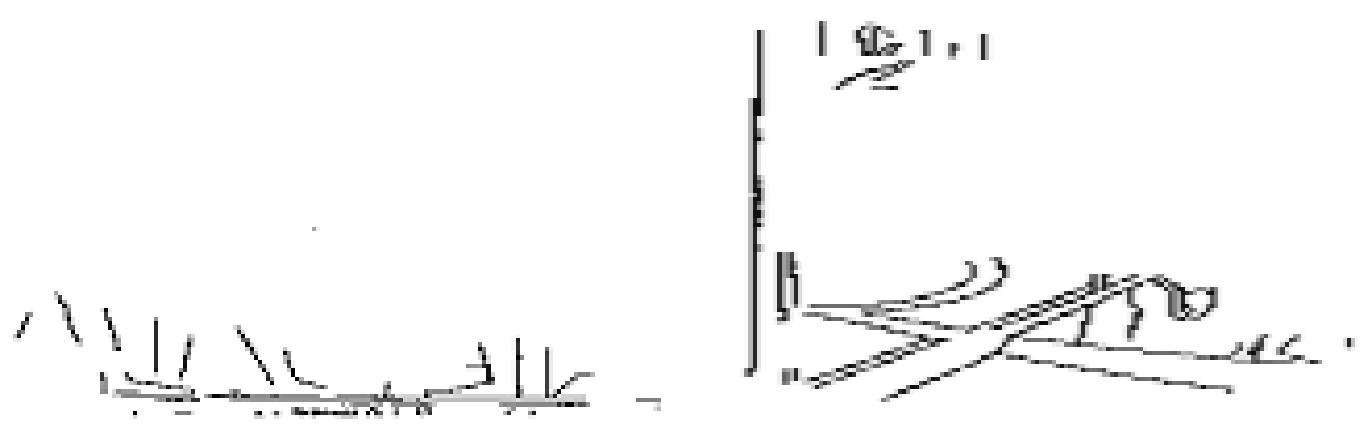

(شكل 9 (

Seele 1959, pl.38 المنظرالثانى(الساعة السابعة من كتاب البوابات) نقلا عن

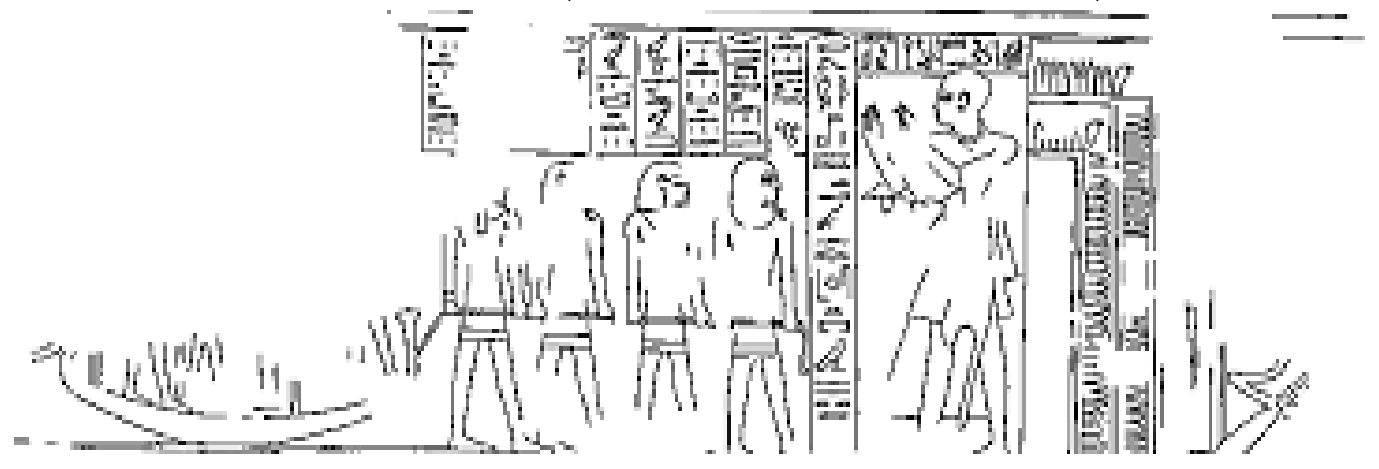

V०Y 
(شكل · (1)

Seele 1959, المنظر الثالث (الساعة الثامنة من كتاب البوابات وباية الساعة التاسعة) نقلا عن pl.37

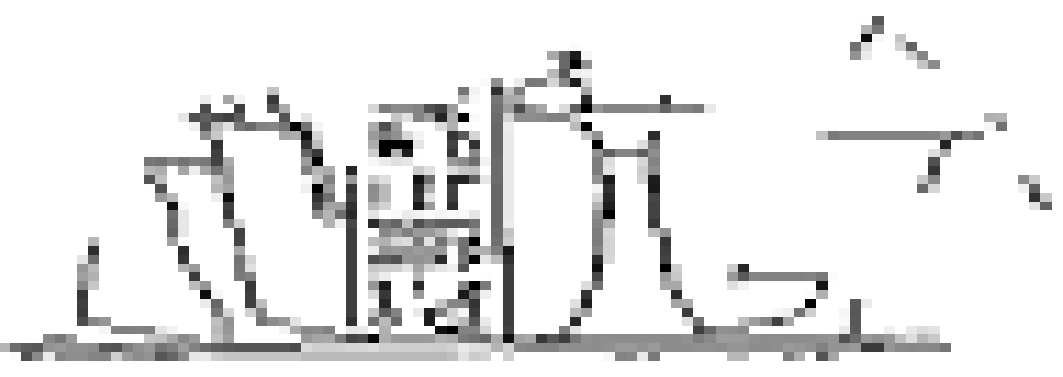

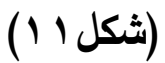

Seele 1959:pl.36:المنظر الثالث(بقية الساعة التاسعة من كتاب البوابات)نقلا عن

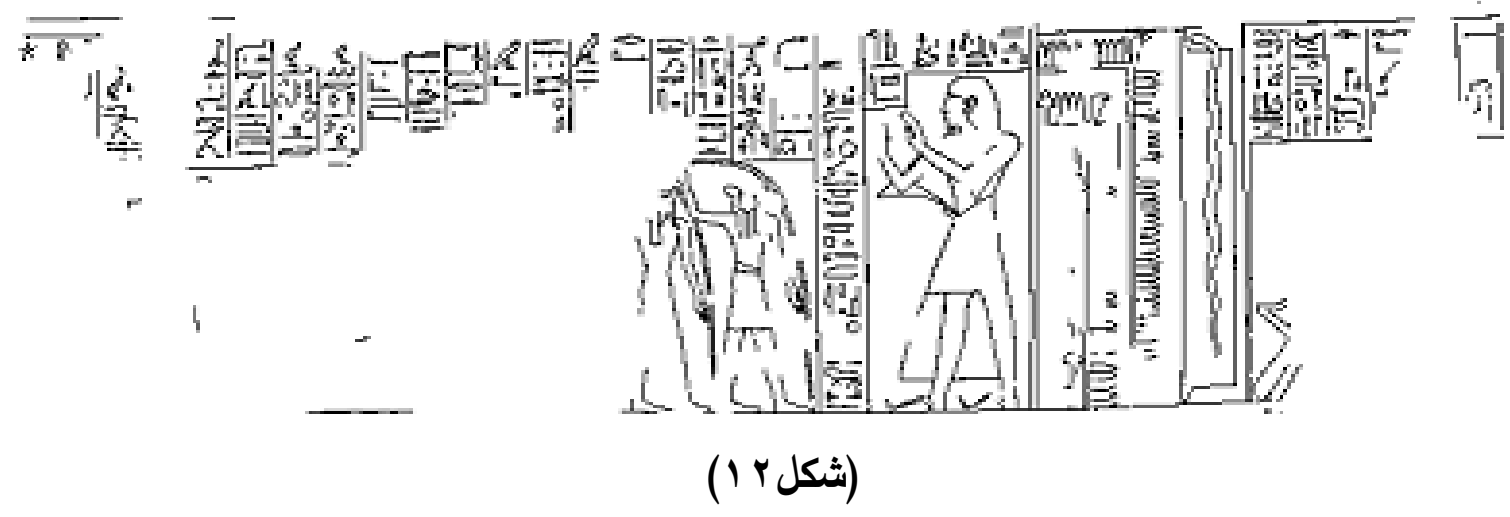

المنظر الرابع (الساعة العاشرة من كتاب البوابات وبداية الساعة الحادية عشر) نقلا عن: Seele

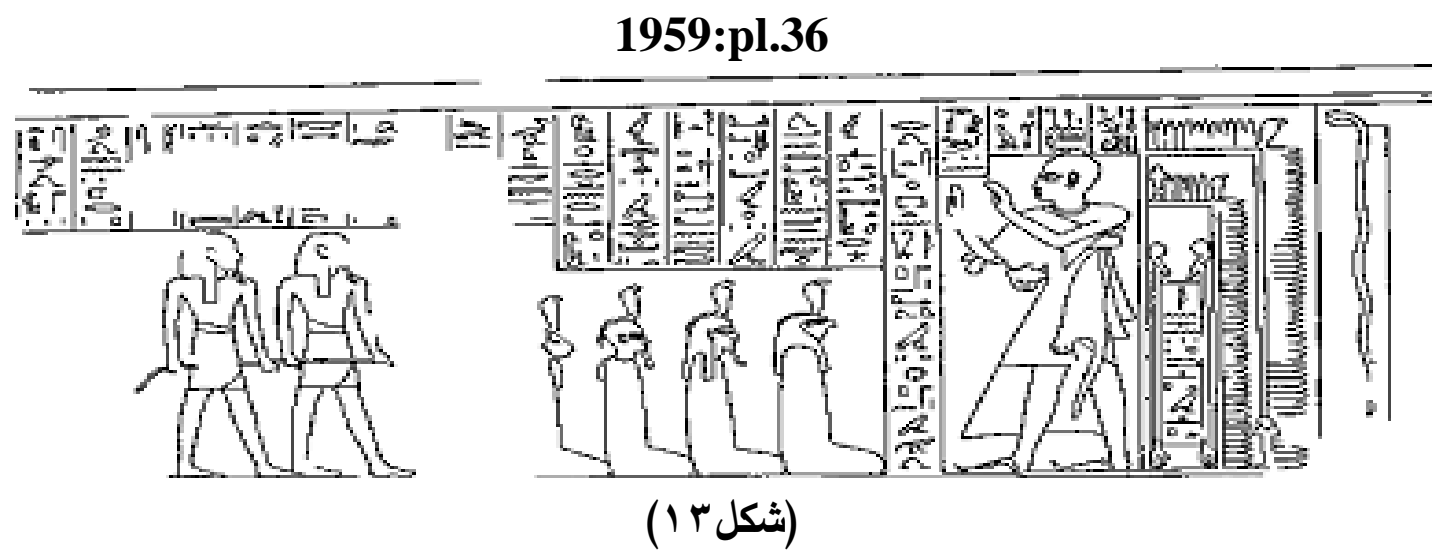

Seele 1959:pl.35:المنظر الخامس (بقية|لساعة الحادية عشرمن كتاب البوابات) نقلاعن 


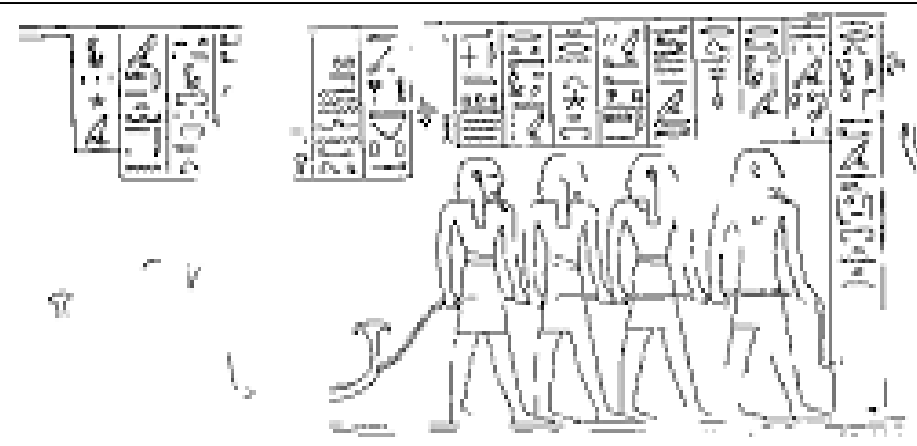

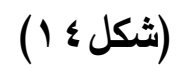

Seele 1959:pl.35:المنظرالخامس (الساعة الثانية عشرمن كتاب البوابات) نقلا عن الن

Fisher, C.S.

7. 1924 A Group of Theban Tombs: Work of the Eckley B. Coxe Jr. Expedition to Egypt, $U M J$ 15. 28ff.

Frankfort, $\mathbf{H}$.

8. 1933 The Cenotaph of Seti I at Abydos, II, London.

Gaballa, A., Kitchen, K.

9. 1981 "The Prophet Amenemope, his tomb and family,Ramesside Varia IV", MDAIK 37, 160-181.

Gardiner, A. H., Wiegall, A.

10. 1913 Topographical Catalogue of the Private Tombs of Thebes Necropolis, London.

\section{Haring, Ben J.J.}

11. 2006 The Tomb of Sennedjem (TT 1) in Deir el-Medina: Palaeography $(=$ Paléographie hiéroglyphique, 2). Cairo: IFAO.

\section{Hornung, E.}

12. 1971 Das Grab des Haremhab im Tal der Könige, Bern.

13. 979-1980 Das Buch von den Pforten des Jenseits nach

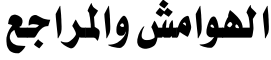

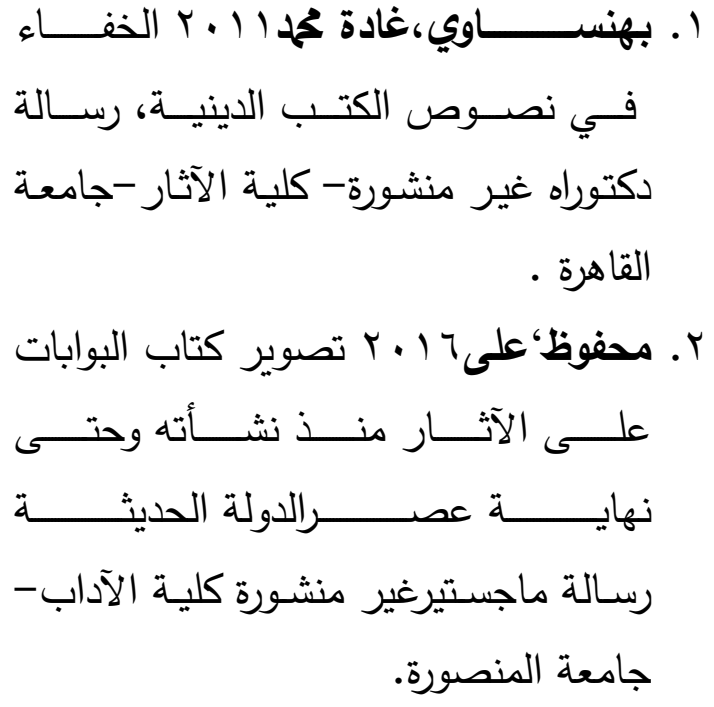

\section{Bonomi, j., Sharpe, S.}

3. 864 The Alabaster Sarcophagus of Oimenptah I King of Egypt, London

\section{Bruyère, $B$.}

4. 1959 La Tombe No 1 de Sen-nedjem à Deir el Médineh (= MIFAO, 88). Cairo.

\section{Champollion,J.}

5. 1844 Monumemts d'Egypte et Nubie: Notices Descriptives, I, Paris

CT

6. 1961 De Buck, A., The Ancient Egyptian Coffin Texts, VII, Chicago, University of Chicago press. 
Piankoff, A.

22. 1954

Ramsses

Series

Pantheon.

\section{PM}

23. 1927 Porter, B., Moss,

L.B. Topographical Bibliography of Ancient Egyptian

Hieroglyphic

Texts, Reliefs and

Paintings, Vol. I², Oxford

\section{PN I}

24. 1935 Ranke,H.,

Altägyptischen

Personennamen,I,Glückstadt 1935.

Seele, K. C.

25. 1959 The Tomb of Tjanefer at Thebes, in: Oriental Institut Publications, Vol. LXXXV1, University of Chicago.

Shedid, A.

26. 1990 Das Grab der Königin Nefertari, München.

27. 1994 Das Grab des Sennedjem, Mainz: von Zabern.

Stephen,W.C.

28. 2010 "An Alabaster Coffin and Sety I's Last Secret", in: AE, Feb/March, 22.

Varille, A.

29. 1935 "Trois nouveaux chants de harpists", in: BIFAO $35,153-160$

\section{Wilding, D.}

30. 1984 Das Grab der Nefertari, Munchen, Haus der Kunst. den Versionen des Neuen

Reiches, AH 7-8, Genève.

14. 1999 The Ancient Egyptian Books of the Afterlife, Cornell University.

\section{Lepsius, K.R.}

15. 1900 Denkmäler aus Aegypten und Aethiopien, Text, III, Leipzig.

\section{Lesko, $\mathbf{L}$.}

16. 972 The Ancient Egyptian Book of the Two Ways, Berkeley: University of California press.

Maninche, $\mathbf{L}$.

17. 2011 Lost Ramessid and Post-Ramessid Private Tombs in the Theban Necropolis, The

Carsten Niebuhr Institute of Near Eastern Studies, University of Copenhagen.

\section{McDonald, J.}

18. 1996 House of Eternity, the Tomb of Nefertari, Los Angeles

\section{Ockinga, $B$.}

19. 2009

The

Tomb of Amenemope (TT 148), Vol.I, Architecture, Texts and Decoration, The Australian Center for Egyptology, Macquarie University, Report

Peet, T.E.

20. 1930 The Great Tomb Robberies of the Twentieth Egyptian Dynasty, Oxford.

Piankoff, A., Maystre, Ch.

21. 1939-1962 le Livre des Portes,3 Vols., MIFAO 74,75,90, Cairo. 
32. 1969 The Book of Gates, in: Liber Amicorum,

Studies Bleeker, Leiden.
31. 1971 Erman, A, Grapow, H., Worterbuch des Aegyptischensprache, III, IV., ( $2^{\text {nd }}$ ed.) Berlin- Leipzig.

Zandee, J. 